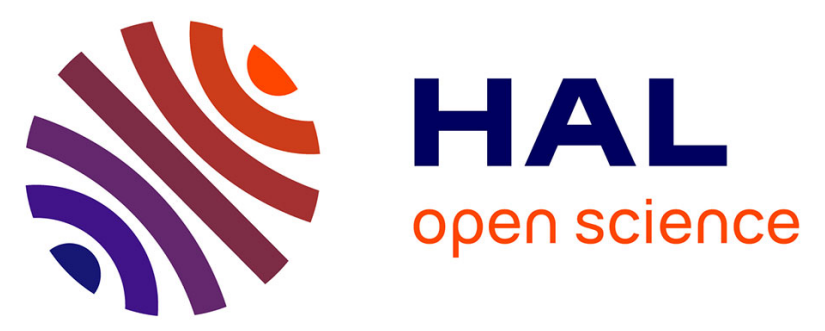

\title{
Structures of Plutonium(IV) and Uranium(VI) with N,N-Dialkyl Amides from Crystallography, X-ray Absorption Spectra and Theoretical Calculations
}

Eléonor Acher, Yanis Hacene Cherkaski, Thomas Dumas, Christelle Tamain, Dominique Guillaumont, Nathalie Boubals, Guilhem Javierre, Christoph Hennig, Pier Lorenzo Solari, Marie-Christine Charbonnel

\section{To cite this version:}

Eléonor Acher, Yanis Hacene Cherkaski, Thomas Dumas, Christelle Tamain, Dominique Guillaumont, et al.. Structures of Plutonium(IV) and Uranium(VI) with N,N-Dialkyl Amides from Crystallography, X-ray Absorption Spectra and Theoretical Calculations. Inorganic Chemistry, 2016, 55 (11), pp.55585569. 10.1021/acs.inorgchem.6b00592 . cea-02389660

\section{HAL Id: cea-02389660 https://hal-cea.archives-ouvertes.fr/cea-02389660}

Submitted on 2 Dec 2019

HAL is a multi-disciplinary open access archive for the deposit and dissemination of scientific research documents, whether they are published or not. The documents may come from teaching and research institutions in France or abroad, or from public or private research centers.
L'archive ouverte pluridisciplinaire HAL, est destinée au dépôt et à la diffusion de documents scientifiques de niveau recherche, publiés ou non, émanant des établissements d'enseignement et de recherche français ou étrangers, des laboratoires publics ou privés. 


\section{Structures of Plutonium(IV) and Uranium(VI) with}

\section{N,N-Dialkyl Amides from Crystallography, X-ray}

\section{Absorption Spectra and Theoretical Calculations}

Eléonor Acher, ${ }^{a}$ Yanis Hacene Cherkaski, ${ }^{a}$ Thomas Dumas ${ }^{a}$, Christelle Tamain, ${ }^{a}$ Dominique Guillaumont, ${ }^{a}$ Nathalie Boubals, ${ }^{a}$ Guilhem Javierre, ${ }^{a}$ Christoph Hennig, ${ }^{b}$ Pier Lorenzo Solari, ${ }^{c}$ Marie Christine Charbonnel ${ }^{a}$

${ }^{a}$ CEA Marcoule, Nuclear Energy Division, RadioChemistry \& Processes Department, DRCP 30207 Bagnols-sur-Cèze, France Bagnols sur Cèze, France

b Helmholtz-Zentrum Dresden-Rossendorf, Institute of Resource Ecology, Bautzner Landstr. 400, 01314 Dresden, Germany

${ }^{\mathrm{c}}$ Synchrotron SOLEIL, L’Orme des Merisiers, BP 48, St Aubin, 91192 Gif sur Yvette, France KEYWORDS Monoamide, uranyl, plutonium, structure, DFT, EXAFS, ab initio debye-waller

\section{ABSTRACT}

The structures of plutonium(IV) and uranium(VI) ions with a series of $N, N$-dialkyl amides ligands with linear and branched alkyl chains were elucidated from single crystal XRD, EXAFS and theoretical calculations. In the field of nuclear fuel reprocessing, $N, N$-dialkyl amides are 
alternative organic ligands to achieve the separation of uranium(VI) and plutonium(IV) from highly concentrated nitric acid solution. EXAFS analysis combined with XRD shows that the coordination structure of $\mathrm{U}(\mathrm{VI})$ is identical in the solution and in the solid state and is independent of the alkyl chain: two amide ligands and four bidentate nitrate ions coordinate the uranyl ion. With linear alkyl chains amides, $\mathrm{Pu}(\mathrm{IV})$ also adopt identical structures in the solid state and in solution with two amides and four bidentate nitrate ions. With branched alkyl chain amides, the coordination structure of $\mathrm{Pu}(\mathrm{IV})$ was more difficult to establish unambiguously from EXAFS. DFT calculations were consequently performed on a series of structures with different coordination modes. Structural parameters and Debye-Waller factors derived from the DFT calculations were used to compute EXAFS spectra without using fitting parameters. By using this methodology, it was possible to show that the branched alkyl chains amide form partly outer-sphere complexes with protonated ligands hydrogen bonded to nitrate ions. 


\section{INTRODUCTION}

Nuclear fuel can be reprocessed to recover major actinides (uranium and plutonium) from spent fuel and to reduce the volume of radioactive waste. Selective separation of actinides is achieved through liquid-liquid extraction technique where the spent fuel is dissolved into an acid aqueous solution and suitable organic ligands are used to extract actinide cations into an organic solution. The main current solvent extraction process is PUREX (Plutonium Uranium Refining by Extraction) in which Tri-n-butyl phosphate (TBP) extractant is used to separate uranium(VI) and plutonium(IV) from fission products in highly concentrated nitric acid solution. TBP has been used for decades but has some limitations such as the formation of degradation products in the presence of strong ionizing radiations. It is thus desirable to identify new families of extractants among which $N, N$-dialkyl amides are the most serious alternative candidates and have received increasing attention. ${ }^{1-19}$ One of the very interesting feature of $N, N$-dialkyl amides is the strong influence of their alkyl groups on their extraction properties. It gives the possibility to tune their extracting strength and selectivity toward uranium (VI) and plutonium (IV) by altering the length and branching of monoamide alkyl chains. ${ }^{1,6,9,20-22}$ The most outstanding effect is obtained upon methyl substitution on the carbon atom adjacent to the carbonyl group which diminishes very strongly plutonium(IV) extraction while uranium(VI) extraction decreases to a much lesser extent. Notwithstanding their strong industrial interest, few basic studies have been reported and the strong influence of $N, N$-dialkyl amides structure on extracting properties is yet to be achieved.

Among the various properties that are important for a comprehensive understanding of selective extraction processes, the stoichiometries and coordination structures of actinide ions in the organic solution can provide crucial information regarding extraction mechanisms. 
Stoichiometries of the extracted actinide species are largely available through solvent extraction data such as the "slope analysis method", which follofws the variation of actinide distribution ratio as a function of monoamide concentration. Uranyl extraction by $N, N$-dialkyl amide ligands (L) has been the subject of numerous solvent extraction investigations. ${ }^{6,11,12,15,23,24}$ It has been shown that uranyl is solubilized in the organic phase as the neutral $\mathrm{UO}_{2}\left(\mathrm{NO}_{3}\right)_{2}(\mathbf{L})_{2}{ }^{6},{ }^{12}, 17,21,24$ Alternatively, plutonium complexes formed in the organic solution are not as well characterized than those with uranium. The stoichiometric number of amide ligands in plutonium complexes varies from 2 to 3 and tends to vary with the branching of their alkyl groups. ${ }^{5-9,22,23,25,26}$ At high nitric acid concentration in the aqueous phase, it has been suggested that uranium and plutonium are extracted as a nitrate anionic species with no inner-sphere complexation of amide ligands. ${ }^{6,26}$ However, the formation of these species has not been further investigated. The knowledge of the stoichiometries of the extracted species is essential but do not provide insight into actinide inneror outer sphere coordination and actinide coordination structures are largely unknown. More insight can be gained from crystal structures and direct spectroscopic measurements in organic solution. Crystal structures have been reported for uranyl with $N, N$-dialkyl amide ligands where uranyl is surrounded by two trans $N, N$-dialkyl amide ligands and two nitrate ions. ${ }^{24,27-30}$ Crystal structures are very scarce for plutonium molecular compounds and there is no known X-Ray Diffraction (XRD) structures for Pu(IV) with amide ligands. Extended X-ray Absorption Finestructure Spectroscopy (EXAFS) is a particularly powerful technique for determining local atomic environment of actinide ions and it has been applied to uranyl in the presence of a N,Ndialkyl amide ligand. ${ }^{31}$ To the best of our knowledge, no EXAFS investigation has been reported for $\mathrm{Pu}(\mathrm{IV})$ with amide ligands. 
Herein, we have combined EXAFS with crystallography and theoretical calculations in order to elucidate the structures of plutonium(IV) and uranium(VI) ions with a series of $N, N$-dialkyl amide ligands. To investigate the influence of alkyl substituents on actinides solvent extraction, $\mathrm{N}, \mathrm{N}$-dialkyl amides with linear and branched alkyl groups on the carbon of their carbonyl group were selected; $\quad N, N$-di(2-ethylhexyl)-iso-butanamide (DEHiBA), $\quad N, N$-di(2-ethylhexyl)-nbutanamide (DEHBA) and N,N-di(2-ethylhexyl)-3,3-dimethyl butanamide (DEHDMBA) (Chart 1). For the crystallographic study, a short- alkyl-chains ligand (N,N-dibutyl- butanamide DBBA, chart 1) was chosen in order to promote crystallization. Very few solid-state crystallographic structures are available for transuranic elements but they provide important starting points to probe actinide coordination structures. The determination of structures from EXAFS is based on the fit of parameters (such as interatomic distances and Debye-Waller factors) for a given structural model (EXAFS simulation best-fit procedure). Yet, for actinide ions with a flexible coordination sphere it is difficult to extract accurate structural information solely from EXAFS data. In the present work, the crystal data were used as reference structural models for EXAFS interpretation. However, for plutonium(IV) complexes in organic solution, it was not possible to resolve unambiguously plutonium coordination structures for all the series of ligands. To help EXAFS analysis, quantum chemical calculations were further performed for plutonium complexes with model amide ligands (DEPA and DEiBA, chart 1). Quantum chemical calculations are increasingly used to provide structural models for actinide complexes in solution and to improve the quality of the fitting procedure. Alternatively, recent advances in EXAFS calculations may allow the determination of multiple-scattering XAFS Debye-Waller (DW) factors from ab initio calculations. ${ }^{32-34}$ To the best of our knowledge, it has not been applied to actinide complexes although it gives the possibility to compute theoretical EXAFS spectra from 
ab initio DW factors and structural parameters without using fitting parameters. In the following parts, we will show that by computing directly theoretical EXAFS spectra, we uncover differences in $\mathrm{Pu}(\mathrm{IV})$ coordination structures in solution.<smiles>CCCCC(CCC)CN(CC(CC)CCC)C(=O)CCC</smiles>

DEHBA

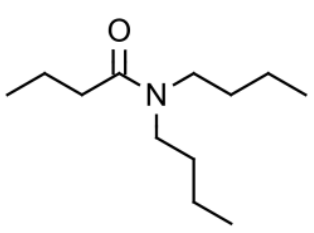

DBBA<smiles>CCCCC(CC)CN(C(=O)C(C)C)C(CC)CCCC</smiles>

DEHiBA<smiles>CCC(=O)N(CC)CC</smiles>

DEPA



DEHDMBA<smiles>CCN(CC)C(=O)C(C)C</smiles>

DEiBA

Chart 1. Studied $N, N$-dialkyl amide ligands

\section{EXPERIMENTAL SECTION}

\section{Reagents}

All experiments on transuranium elements were conducted in the Atalante facility (CEA Marcoule, France), in a laboratory dedicated to the structural study of these highly radioactive elements. All experiments were carried out with approved safety operating procedures in negative pressure glove box. Depleted uranyl nitrate from Prolabo, $\mathrm{UO}_{2}\left(\mathrm{NO}_{3}\right)_{2} \cdot 6 \mathrm{H}_{2} \mathrm{O}$, purity $99.9 \%$, was used without further purification. ${ }^{239,}{ }^{240} \mathrm{Pu}(\mathrm{IV})$ solution was prepared by dissolving the corresponding oxide, $\mathrm{PuO}_{2}$, with concentrated $\mathrm{HNO}_{3}$ in a glove box. It was then purified by fixation on a DOWEX anion exchange resin at $7 \mathrm{~mol} \cdot \mathrm{L}^{-1} \mathrm{HNO}_{3}$ and elution with $0.5 \mathrm{~mol} \cdot \mathrm{L}^{-1}$ 
$\mathrm{HNO}_{3}$. Oxidation state and concentration of the actinide solutions were checked by Vis-NIR spectrophotometry.

Ammonium Cerium nitrate, $\left(\mathrm{NH}_{4}\right)_{2} \mathrm{Ce}\left(\mathrm{NO}_{3}\right)_{6}$ (Aldrich, $98.5 \%$ Reagent grade) was used to prepare Ce(IV) solutions to simulate An(IV) solutions in pseudoactive experiments, considering some chemical analogies between $\mathrm{Ce}(\mathrm{IV})$ and An(IV) ions.

Diisopropyl ether, toluene and $n$-dodecane were purchased from Aldrich. TPH (hydrogenated tetrapropylene) is an industrial diluent used in AREVA's reprocessing plant. All other reagents $\left(\mathrm{HNO}_{3}, \mathrm{LiNO}_{3}\right)$ were furnished by VWR Co.

DBBA, DEHDMBA, DEHBA and DEHiBA $N, N$-dialkyl amides were synthesized by Pharmasynthese (France).

\section{Synthesis of solid-state compounds}

Single crystals of U-DBBA were synthesized by dissolution of $87 \mathrm{mg}$ of DBBA in $1 \mathrm{~mL}$ of diisopropyl ether. Solid uranyl nitrate was added up to $0.2 \mathrm{~mol} . \mathrm{L}^{-1}$ using a 1:2.5 metal:ligand molar ratio. The slow evaporation of the mixture gave some suitable single crystals (Figure 1).

The plutonium-monoamide complex Pu-DBBA was prepared by volume to volume extraction of a $0.25 \mathrm{~mol} . \mathrm{L}^{-1} \mathrm{Pu}(\mathrm{IV})$ nitric acid solution containing $7 \mathrm{~mol} \cdot \mathrm{L}^{-1}$ of lithium nitrate by DBBA $\left(0.25\right.$ mol. $\left.\mathrm{L}^{-1}\right)$ diluted in toluene. The organic phase was separated and its solvent was evaporated to dryness allowing the formation of very small crystals. A small accurate volume of toluene allowing the dissolution of the crystals was added. X-ray quality crystals were grown by vapor diffusion of hexane in this toluene solution. Isostructural Ce-DBBA single crystals were also grown according to the same procedure. Photos of the crystals are given on Figure 1. 

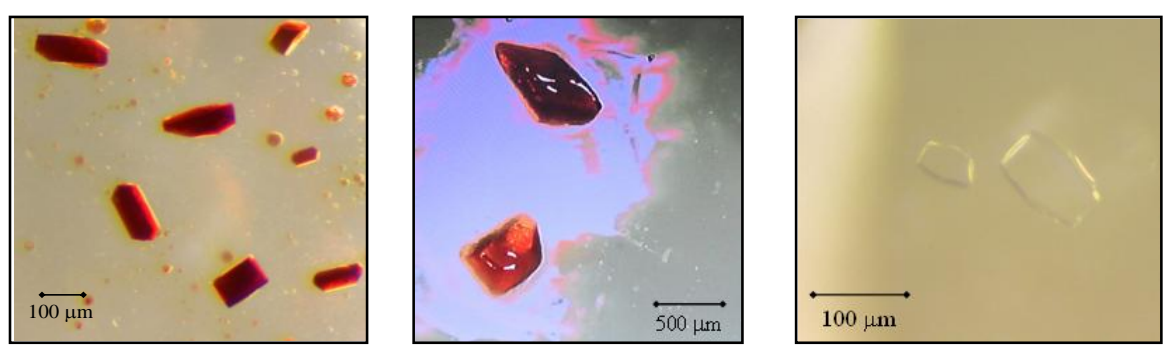

Figure 1: Photos of Ce-DBBA (left), Pu-DBBA (middle), and U-DBBA (right).

\section{EXAFS sample preparation}

For solid compounds, U-DBBA-S and Pu-DBBA-S, pellets were prepared with one milligram of single crystals strongly grounded with polyethylene powder. DBBA liquid samples were prepared by dissolution of single crystals in toluene up to $5.10^{-3} \mathrm{~mol} . \mathrm{L}^{-1}$ for the uranium solution (U-DBBA-L) and $1.10^{-3}$ mol.L $\mathrm{L}^{-1}$ for the plutonium sample (Pu-DBBA-L).

The DEHDMBA, DEHBA and DEHiBA samples were prepared by liquid-liquid extraction at $25^{\circ} \mathrm{C}$. Nitric acid aqueous phases $\left(\left[\mathrm{HNO}_{3}\right]=3 \mathrm{~mol} \cdot \mathrm{L}^{-1}\right)$, containing the radionuclides $(\mathrm{U}(\mathrm{VI})$ or $\mathrm{Pu}(\mathrm{IV}))$ were contacted for 15 minutes by means of an automatic vortex shaker with organic solutions (aqueous phase volume over organic phase volume ratio: Vaq/Vorg = 1) containing the ligand. Before the extraction, the organic phase was pre-equilibrated with 3 mol. $\mathrm{L}^{-1}$ nitric acid $(\operatorname{Vaq} /$ Vorg $=3)$ for $30 \mathrm{~min}$ at $25^{\circ} \mathrm{C}$. The phases were separated after centrifugation. Actinides concentrations in the organic phase were determined by alpha-spectroscopy for plutonium samples and fluorescence spectroscopy for the uranium ones. Table 1 summarizes the experimental conditions for the different samples. The evolution of $\mathrm{Pu}(\mathrm{IV})$ was monitored with Vis-NIR spectrophotometry during several days corresponding to the delay between the samples preparation and their analysis at the Synchrotron. 
Table 1. Compositions of DEHDMBA, DEHBA and DEHiBA solutions used in EXAFS measurements.

\begin{tabular}{cccc}
\hline & Solvant & [Ligand] $\left(\text { mol. }^{-1}\right)^{\mathrm{a}}$ & [Actinide $_{\text {org }}\left(\text { mmol. }^{-1}\right)^{\mathrm{b}}$ \\
\hline \hline U-DEHDMBA & TPH & 1.1 & 40 \\
Pu-DEHDMBA & TPH & 1.0 & 13 \\
U-DEHBA & $n$-dodecane & 1.0 & 6.7 \\
Pu-DEHBA & $n$-dodecane & 1.2 & 2.2 \\
U-DEHiBA & $n$-dodecane & 1.0 & 5.5 \\
Pu-DEHiBA & $n$-dodecane & 1.6 & 3.2 \\
\hline${ }^{\text {a Monoamide concentration in the organic phase. }}{ }^{\mathrm{b}} \mathrm{Pu}(\mathrm{IV})$ or U(VI) concentrations in the organic \\
phase
\end{tabular}

\section{Single crystal $X$-ray diffraction}

To prevent plutonium health hazards, the crystal was mounted on a MicroMount patented by MiTeGen, inserted into a goniometer base. A MicroRT capillary was then drawn over the sample and onto the base where it was sealed by adhesive. The single crystal diffraction intensities were measured on a Nonius four-circle diffractometer equipped with an Apex II CCD at $150 \mathrm{~K}$ using 600 series Cryostream Cooler (Oxford Cryosystem) for uranium compounds and at room temperature for the cerium and plutonium ones. The instrument was equipped with a fine-focus Mo-target X-ray tube $(\lambda=0.71073 \AA)$ operated at $1500 \mathrm{~W}$ and controlled by the APEX2 software package. ${ }^{35}$ Data were integrated with SAINT $^{36}$ and subsequently corrected for absorption with SADABS. ${ }^{37}$ The SHELXTL software package ${ }^{38}$ was employed for structure determination and refinement. Heavy non-hydrogen atoms were located on the difference Fourier map and their positions were refined anisotropically. The main crystal data and details of the 
final refinement are reported in Table 2. For both $\mathrm{Pu}(\mathrm{IV})$ and $\mathrm{Ce}(\mathrm{IV})$, carbon atoms of one monoamide butyl chains seem to be disordered on several positions leading to important thermal agitation coefficients. Distance constrains were added to the corresponding alkyl chain. Concerning the plutonium resolution, the positions of carbon atoms of two chains of this disordered monoamide ligand were split and partial occupation rates were given to the corresponding atoms to decrease the thermal agitation of the alkyl chain carbon atoms. Nevertheless, the thermal ellipsoids are larger for plutonium and cerium compounds (Pu-DBBA and Ce-DBBA) than for the uranium ones and for technical reason it was not possible to collect the data at low temperature.

Table 2. Crystal data and final refinement.

\begin{tabular}{cccc}
\hline Compound & U-DBBA & Ce-DBBA & Pu-DBBA \\
\hline Formula & $\mathrm{UO}_{2}\left(\mathrm{NO}_{3}\right)_{2}(\mathbf{D B B A})_{2}$ & $\mathrm{Ce}\left(\mathrm{NO}_{3}\right)_{4}(\mathbf{D B B A})_{2}$ & $\mathrm{Pu}\left(\mathrm{NO}_{3}\right)_{4}(\mathbf{D B B A})_{2}$ \\
Temperature & $150 \mathrm{~K}$ & $296 \mathrm{~K}$ & $296 \mathrm{~K}$ \\
Formula weight $\left(\mathrm{g} \cdot \mathrm{mol}^{-1}\right)$ & 792.7 & 736.42 & 838.3 \\
Crystal size $(\mu \mathrm{m})$ & $0.2 \times 0.09 \times 0.02$ & $0.10 \times 0.07 \times 0.2$ & $1 \times 0.5 \times 0.4$ \\
Crystal system & Orthorhombic & Monoclinic & Monoclinic \\
Space group & $\mathrm{P} 2_{1} 2_{1} 2_{1}$ & $\mathrm{C} 2 / \mathrm{c}$ & $\mathrm{C} 2 / \mathrm{c}$ \\
$\mathrm{a}, \AA$ & $9.69(1)$ & $35.08(2)$ & $35.34(1)$ \\
$\mathrm{b}, \AA$ & $18.38(1)$ & $10.74(1)$ & $10.88(1)$ \\
$c, \AA$ & $19.37(1)$ & $20.08(2)$ & $20.33(1)$ \\
Beta $\left({ }^{\circ}\right)$ & - & $111.10(1)$ & $110.6(1)$ \\
Volume, $\AA^{3}$ & $3450.60(2)$ & $7058.90(1)$ & $7310.40(1)$ \\
$\mathrm{Z}$ & 4 & 8 & 8 \\
$\rho_{\text {calc }}, \mathrm{g} \cdot \mathrm{cm}^{-3}$ & 1.590 & 1.340 & 0.0358 \\
$\mathrm{R}[\mathrm{I}>2 \mathrm{sigma}(\mathrm{I})]$ & 0.0355 & 0.0615 & 0.1022 \\
$\mathrm{R}$ indices $($ all data $)$ & 0.0746 & 0.1613 & \\
\hline
\end{tabular}




\section{EXAFS data acquisition and treatment}

All measurements were performed at room temperature in $200 \mu \mathrm{L}$ double-layered cells specifically designed for radioactive samples. All spectra were recorded at the actinide $\mathrm{L}_{3}$ edge (17166 eV for $\mathrm{U}$ and $18057 \mathrm{eV}$ for $\mathrm{Pu}$ ). The data represent averages of 5 scans for Pu-DBBA-L and U-DBBA-L liquid samples, and 8 and 4 scans for the two Pu-DBBA-S and U-DBBA-S solid samples, respectively. Data processing was carried out with the Athena code. ${ }^{39}$ After energy calibration, the $\mathrm{E}_{0}$ energy was set at the maximum of the absorption edge (the XANES spectra are given in Supplementary Information, Figure S1). For all the samples, the maximum energy of the absorption edge confirms the redox state + VI for uranium $(17178.6 \mathrm{eV})$ and $+\mathrm{IV}$ for plutonium $(18068.2 \mathrm{eV}) .^{40,41}$ The EXAFS signal was extracted by subtracting a linear preedge background and a combination of cubic spline functions for atomic absorption background and then normalized by the Lengeler-Eisenberg procedure. Pseudo-radial distribution functions (PRDF) were obtained by Fourier transform in $\mathrm{k}^{3} \chi(\mathrm{k})$ using the ATHENA code between 1.5 and $12.5 \AA^{-1}$ for plutonium samples and between 2.5 and $13.5 \AA^{-1}$ for uranium ones. The $\mathrm{R}$ factor $(\%)$ and the quality factor $\left(\mathrm{QF}\right.$, reduced $\left.\mathrm{chi}^{2}\right)$ of the fits are provided from ARTEMIS. ${ }^{39}$

For EXAFS data analysis, the fitting procedure is based on U-DBBA-S and Pu-DBBA-S XRD structures. Theoretical scattering phases and amplitudes were calculated by the FEFF8.4 code ${ }^{33}$ from the crystallographic parameters. Experimental EXAFS data were then adjusted using seven and six individual two body single scattering paths for uranium and plutonium respectively and six three or four body multiple-scattering paths for uranium and four three or four multiplescattering paths for plutonium. The maximum number of floating parameters (limited by $2 \Delta \mathrm{k} \Delta \mathrm{R} / \pi+2$ ) was determined for both $\mathrm{U}$ and $\mathrm{Pu}$ considering individual coordination shell. $\Delta \mathrm{k}$ 
and $\Delta \mathrm{R}$ are, respectively, $7 \AA^{-1}$ and $1.4 \AA$ in the first coordination shell and $4 \AA^{-1}$ and $2.2 \AA$ in the second coordination shell for uranium and $7 \AA^{-1}$ and $1.2 \AA$ in the first coordination shell and $4 \AA^{-}$ ${ }^{1}$ and $2.2 \AA$ in the second coordination shell for plutonium which allows a maximum number of floating parameter of eight and seven for uranium and plutonium first coordination shell respectively whereas the second shell was limited to seven in both cases. Coordination numbers (CN) were fixed according to the crystal structure. Significant amplitude reductions were noticed on experimental spectra for the two solid samples and the self-absorption effect was corrected in the fitting procedure by lowering the total amplitude reduction factor $\mathrm{S}_{0}{ }^{2}$ to 0.85 and 0.9 for $\mathbf{U}$ DBBA-S and Pu-DBBA-S respectively.

The fit results on model compounds U-DBBA-S and Pu-DBBA-S provided references values to restrict floating metrical parameters such as $\sigma^{2}$ factors and $\Delta \mathrm{R}$ for the liquid samples. In addition to $\Delta \mathrm{E}_{0}$, six floating parameters were taken into account for the first coordination shell of uranium $\left(\Delta \mathrm{R}_{\mathrm{O} \text {-yle }}, \sigma^{2}\right.$ O-yle, $\Delta \mathrm{R}_{\mathrm{O} \text {-amide, }} \sigma^{2}{ }_{\mathrm{O} \text {-amide, }}, \Delta \mathrm{R}_{\mathrm{O} \text {-NO3 }}$ and $\left.\sigma^{2}{ }_{\mathrm{O}-\mathrm{NO} 3}\right)$ and four for the plutonium one $\left(\Delta \mathrm{R}_{\mathrm{O}-}\right.$ amide, $\sigma^{2} \mathrm{O}$-amide, $\Delta \mathrm{R}_{\mathrm{O}-\mathrm{NO} 3}$ and $\sigma^{2}$ O-NO3). The parameters considered for the second coordination sphere were identical for uranium and plutonium: $\Delta \mathrm{R}_{\mathrm{N}-\mathrm{NO} 3}, \sigma^{2}{ }_{\mathrm{N}-\mathrm{NO} 3}, \Delta \mathrm{R}_{\mathrm{C} \text {-amide, }}, \sigma^{2}$ C-amide, $\Delta \mathrm{R}_{\mathrm{O}^{\prime} \text {-NO3 }}$

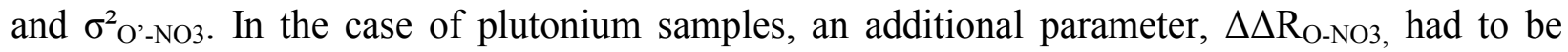
used to fit accurately the first plutonium shell and to obtain reliable values for $\sigma^{2}$ o-NO3. For multiple-scattering paths, $\Delta \mathrm{R}$ and $\sigma^{2}$ were approximated as equal to the corresponding single scattering parameters. Spectra for the eight liquid samples were fitted with the same fixed $\mathrm{CN}$ from crystallographic data and $\mathrm{S}_{0}^{2}=1 . \Delta \Delta \mathrm{R}_{\mathrm{O}-\mathrm{NO} 3}$ parameter was maintained to fit plutonium spectra.

\section{Computational details}


The geometry and frequency calculations have been performed with Gaussian $09^{42}$ at the DFT level of theory with the PBE0 functional. ${ }^{43}$ A small core quasi-relativistic effective core potential (RECP -60 electrons) $)^{44,45}$ by the Stuttgart-Cologne group and its corresponding TZ-valence basis set have been used for $\mathrm{Pu}^{46}$ and the def-TZVP ${ }^{47}$ basis sets for the other atoms. Solvent effects have been taken into account with a polarizable continuum model (IEFPCM) corresponding to $n$-dodecane. ${ }^{42}$

The $a b$ initio DW factors have been calculated at $300 \mathrm{~K}$ for each scattering path from the dynamical matrix extracted from the DFT frequency calculation with the DMDW module of FEFF9. ${ }^{48,49}$ The EXAFS spectra have then been simulated with FEFF9 considering this ab initio DW factors, and all multiple-scattering paths up to a half-path length of $6 \AA$. The scattering potentials were calculated using a self-consistent loop. The amplitude factor $\mathrm{S}_{0}{ }^{2}$ was fixed to 1 as in the EXAFS fitting procedure for the liquid samples. The shift of the photoelectron energy origin $\Delta \mathrm{E}_{0}$ is the only parameter adjusted in the EXAFS simulation and has been taken so that the first amplitudes of the simulated spectra are in phase with the experimental ones.

\section{RESULTS}

\section{$D B B A$ solid-state structures}

The uranyl-monoamide system has been widely studied by single crystal X-ray diffraction. Even if halogen anions are not encountered in $\mathrm{U}$ and $\mathrm{Pu}$ extraction processes, some papers describe complexes containing halogen anion instead of nitrates. ${ }^{50}$ With nitrate counter ion, most reported structures contain short-chains ligands ${ }^{28,27,29,51}$ or cyclic ligands ${ }^{52-56}$ but a few structures with long-chain extractant molecules have also been reported. ${ }^{51} \mathrm{UO}_{2}(\mathbf{D B B A})_{2}\left(\mathrm{NO}_{3}\right)_{2}(\mathbf{U}-$ DBBA), crystallizes in an orthorhombic system with $\mathrm{P} 2{ }_{1} 2_{1} 2_{1}$ space group. Two different metallic 
centers are present in the unit cell but their structural environments are identical. The actinyl $\mathrm{UO}_{2}{ }^{2+}$ cation is coordinated in the equatorial plane to two oxygen atoms from two monoamide ligands and two bidentate nitrates which ensure the charge compensation (Figure 2). The uranyl ion is thus 6-fold coordinated forming a distorted hexagonal bi-pyramid. The main distances and angles of the coordination sphere are gathered in Table 3. With $178.9(2)^{\circ}$, the uranyl angle is consistent with the $180 \pm 5^{\circ}$ of a linear structure. ${ }^{41}$ The average uranyl U-Oyl distance of $1.743(1) \AA$ is slightly shorter than the average value of $1.79 \AA$ given by Burns ${ }^{57}$ (based on the analyzes of hundreds of organic and inorganic uranyl structures) but in agreement with the one reported in uranyl complexes with two bidentate nitrates and two neutral oxygen donor ligands. ${ }^{58}$

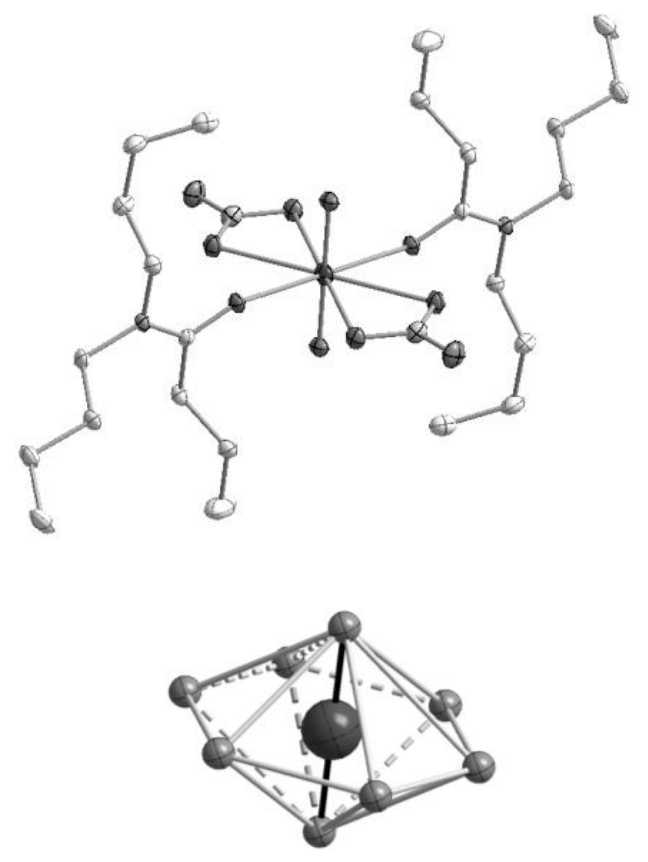

Figure 2. Uranyl cation coordination sphere with displacement ellipsoids at $30 \%$ probability level and its polyhedron in U-DBBA. 
The four $\mathrm{U}-\mathrm{O}_{\mathrm{NO} 3}$ shorter distances, with an average of 2.503(1) $\AA$ are very similar within the coordination sphere and longer than the $\mathrm{U}-\mathrm{O}_{\text {amide }}$ one (2.343(1) $\AA$ ). Compared to free monoamide ligands $\left(\mathrm{d}_{\mathrm{C}=\mathrm{O}}=1.23 \AA, \mathrm{d}_{\mathrm{C}-\mathrm{N}}=1.32-1.34 \AA\right),{ }^{59}$ the $\mathrm{C}=\mathrm{O}$ length increases $\left(\mathrm{d}_{\mathrm{C}=\mathrm{O}}=1.247(1) \AA\right)$ whereas the $\mathrm{C}-\mathrm{N}$ is shortened $\left(\mathrm{d}_{\mathrm{C}=\mathrm{N}}=1.295(1) \AA\right)$. This expected property is related to the electronic delocalization and a greater contribution of the charge-separated resonance form in the complex:

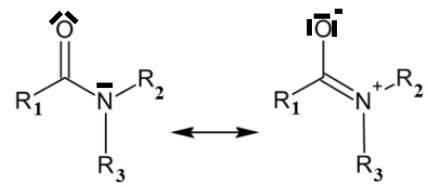

With a U-O-C-N torsion angle of $163.6(1)^{\circ}$, the complex does not show the strong planar torsional preference generally found in this class of complexes. ${ }^{59}$ The steric constraints due to the relatively long alkyl chains force this a priori unstable configuration.

Table 3. Selected single crystal distances and bond angles within U-DBBA, Pu-DBBA and CeDBBA compounds (average values in $\AA$ )

\begin{tabular}{ccccccccc}
\hline & \multicolumn{3}{c}{ Distances $(\AA)$} \\
& $\mathrm{U}=\mathrm{O}$ & $\mathrm{M}-\mathrm{O}_{\text {amide }}$ & $\mathrm{M}-\mathrm{O}_{\mathrm{NO} 3}$ & $\mathrm{C}=\mathrm{O}$ & $\mathrm{C}-\mathrm{N}$ & $\mathrm{O}=\mathrm{U}=\mathrm{O}$ & $\mathrm{M}-\mathrm{-O}-\mathrm{C}$ & $\mathrm{M}--\mathrm{O}-\mathrm{C}-\mathrm{N}$ \\
\hline \hline U-DBBA & $1.743(1)$ & $2.343(1)$ & $2.503(1)$ & $1.247(1)$ & $1.29(1)$ & $178.9(2)$ & $152.9(1)$ & $163.6(1)$ \\
Ce-DBBA & - & $2.244(5)$ & $2.454(7)$ & $1.30(1)$ & $1.24(1)$ & - & $158.2(6)$ & $136.3(9)$ \\
Pu-DBBA & - & $2.26(1)$ & $2.44(1)$ & $1.29(1)$ & $1.26(1)$ & - & $157.8(1)$ & $136.1(5)$ \\
\hline
\end{tabular}

In addition to plutonium Pu-DBBA, the crystal structure was also determined for the analogous lanthanide $\mathrm{Ce}(\mathrm{IV}) . \mathrm{Pu}(\mathbf{D B B A})_{2}\left(\mathrm{NO}_{3}\right)_{4}$ and isomorphic $\mathrm{Ce}(\mathbf{D B B A})_{2}\left(\mathrm{NO}_{3}\right)_{4}$, are characterized by a monoclinic symmetry. To the best of our knowledge, it is the first reported structure for a tetravalent ion complex (including lanthanides) with monoamide and nitrate ions. 
Only one structure of a tetravalent uranium complex with a monoamide was previously described corresponding to uranium-diethylpropanamide with chloride ions. ${ }^{60}$ The single metallic atom in the unit cell is coordinated to two oxygen atoms from two monoamides and eight oxygen atoms from four bidentate nitrate groups (Figure 3). The metallic cation is 10-fold coordinated forming a very distorted bicapped dodecahedron.

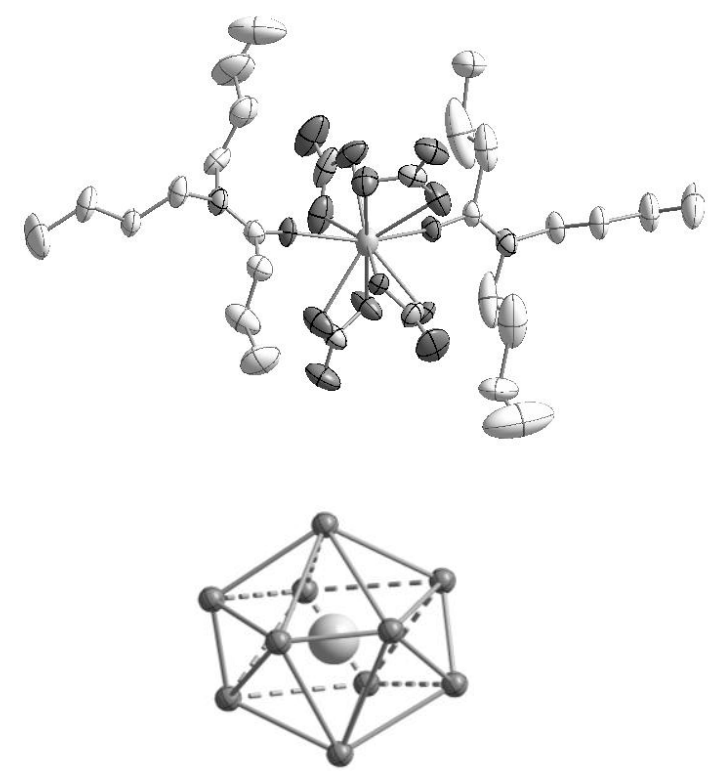

Figure 3. Plutonium cation coordination sphere with displacement ellipsoids at $30 \%$ probability level and its polyhedron in Pu-DBBA.

The main distances and angles are reported in Table 3. As for the uranyl compound, the average nitrate distances with the metallic cation $\left(<\mathrm{d}_{\mathrm{Pu}-\mathrm{O}(\mathrm{NO} 3)}>=2.43(1) \AA,<\mathrm{d}_{\mathrm{Ce}-\mathrm{O}(\mathrm{NO} 3)}>=\right.$ $2.457(1) \AA)$ are longer than the monoamide ones $\left(<\mathrm{d}_{\mathrm{Pu}-\mathrm{O}(\text { amide })}>=2.26(1) \AA,<\mathrm{d}_{\mathrm{Ce}-\mathrm{O}(\text { amide })}>=\right.$ 2.250(1) $\AA$ ). The longer $\mathrm{Ce}-\mathrm{O}_{\text {amide }}$ distances compared to the $\mathrm{Pu}-\mathrm{O}$ ones are in agreement with the ionic radii $\left(\mathrm{R}_{\mathrm{Ce}(\mathrm{IV})}=0.97 \AA, \mathrm{R}_{\mathrm{Pu}(\mathrm{IV})}=0.96 \AA\right.$ determined for coordination number 8$) .{ }^{61}$ For the plutonium structure, it is interesting to note that two types of distances are observed concerning the coordinated nitrates. For each nitrate ion, one oxygen atom is closer $\left(\mathrm{Pu}-\mathrm{O}_{\mathrm{NO} 3}=\right.$ 
$2.42(1)-2.45(1) \AA)$ than the other one $\left(\left(\mathrm{Pu}-\mathrm{O}_{\mathrm{NO} 3}=2.44(1)-2.47(1) \AA\right)\right.$ leading to slightly asymmetric bidentate nitrates. This phenomenon is also observed to for the Ce(IV) structure with $<\mathrm{d}_{\mathrm{Ce}-\mathrm{O}(\mathrm{NO} 3)}>=2.44(1)-2.46(1) \AA$ and $\left\langle\mathrm{d}_{\mathrm{Ce}-\mathrm{O}(\mathrm{NO} 3)}\right\rangle=2.45(1)-2.48(1) \AA$. This trend may be related to a slightly sterically constrained coordination sphere. Asymmetric binding mode of nitrate ligands have been reported in congested coordination environment of $\mathrm{Pu}(\mathrm{IV}){ }^{62}$ The same evolution as for the uranyl single crystal is observed concerning the distances within the monoamide: the $\mathrm{C}_{\text {amide }}-\mathrm{O}_{\text {amide }}$ bond lengths increase and the $\mathrm{C}_{\mathrm{amide}}-\mathrm{N}_{\text {amide }}$ ones decrease compared to the free amide. ${ }^{59} \mathrm{Ce}-\mathrm{O}_{\text {amide }}$ distances are found shorter than the $\mathrm{Pu}-\mathrm{O}_{\text {amide }}$ ones despite the larger ionic radii of $\mathrm{Ce}(\mathrm{IV}) .{ }^{61}$ This can be due to the steric constraints of the closer bidentate nitrate ligands disturbing the monoamide complexation for $\mathrm{Pu}(\mathrm{IV})$.

\section{EXAFS data analysis}

EXAFS spectra have been recorded at the actinide $\mathrm{L}_{3}$ edge in order to characterize the actinide coordination sphere in the organic phase. Data adjustments, based on the XRD structures, have been carried out to extract structural parameters such as interatomic distances $(R)$ and DebyeWaller factors $\left(\sigma^{2}\right)$. Coordination numbers were fixed. Figure 4 displays the $\mathrm{k}^{3}$-weighted EXAFS spectra of each solution sample and solid-state compound, superimposed with the best-fit results obtained using the crystallographic model. The corresponding Fourier transforms (FT) and imaginary part of the Fourier Transforms are shown in Figure 5 for both cations. 

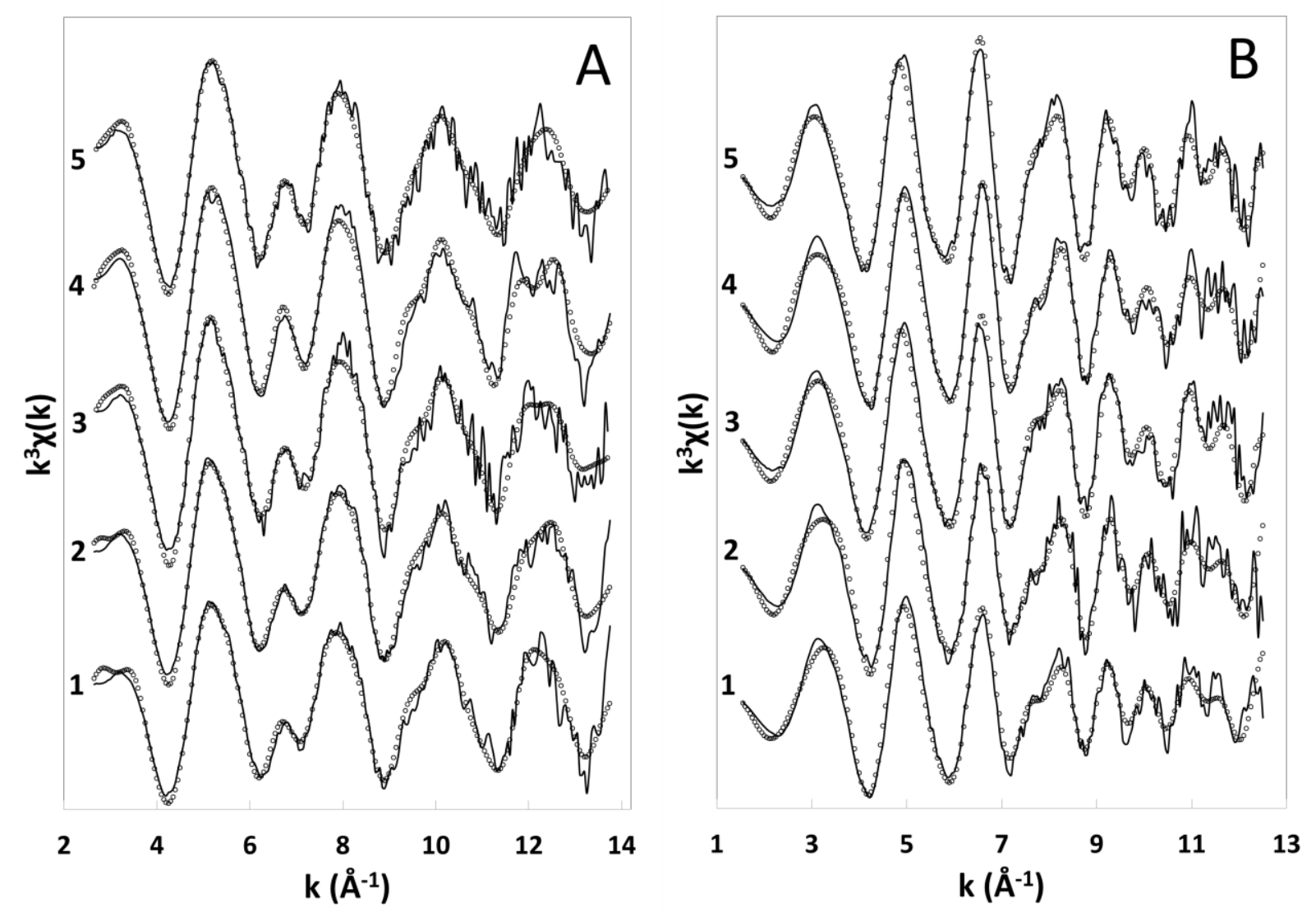

Figure 4. $\mathrm{k}^{3}$-weighted EXAFS spectra at uranium (A) and plutonium (B) $\mathrm{L}_{3}$ edge (full lines) and best fit results (open circle) for (1) An-DBBA-S, (2) An-DBBA-L, (3) An-DEHBA, (4) AnDEHDMBA and (5) An-DEHiBA (An = U, Pu). 

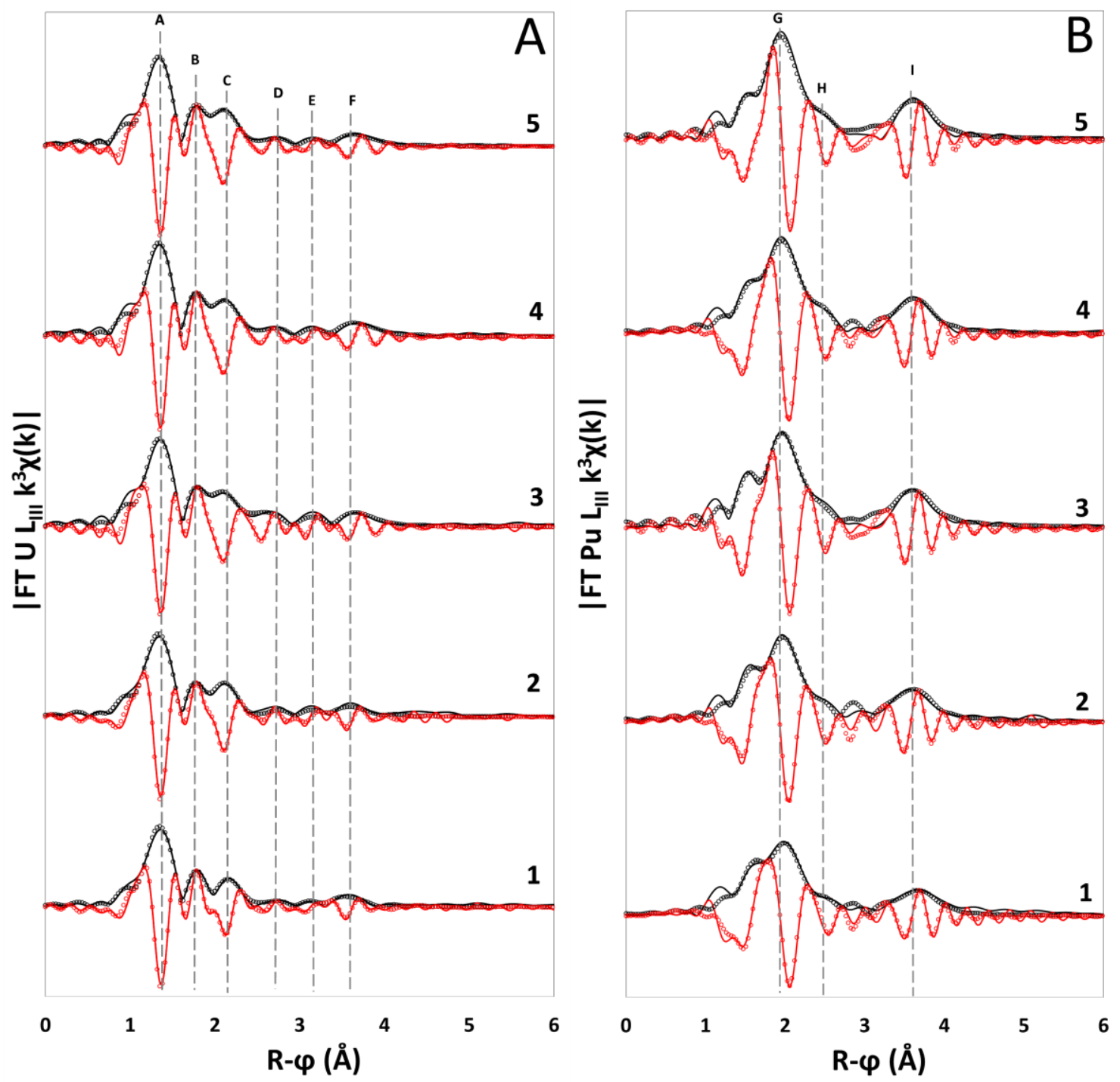

Figure 5. Experimental FT's modulus part (black line) and fit (black open circle) and experimental FT's imaginary part (red line) and fit (red open circle) at uranium (A) and plutonium (B) L $L_{3}$ edge for (1) An-DBBA-S, (2) An-DBBA-L, (3) An-DEHBA, (4) AnDEHDMBA and (5) An-DEHiBA (An = U, Pu).

Experimental EXAFS spectra for uranium samples are presented in Figure 4A. Amplitudes and frequencies of the $\mathrm{k}^{3}$-weighted EXAFS signal are similar for all the samples. They are also 
similar to the one obtained by Yaita at al. for the $\mathrm{UO}_{2}\left(\mathrm{NO}_{3}\right)_{2} \cdot 2 \mathrm{DH}_{3} \mathrm{EHA}(\mathrm{N}, \mathrm{N}-$ dihexyl-3ethylhexanamide) complex in dodecane solution. ${ }^{63}$. Moreover, no significant differences were found for EXAFS spectra between DEHiBA and DEHBA samples which were recorded within the same experimental conditions (in $n$-dodecane and with similar uranyl concentrations).

The EXAFS spectra are dominated by the 2 axial O-yl contributions as observed on the FT (Figure 5A, peak A). Contributions at $\mathrm{R}+\varphi<1.2 \AA$ are low frequencies spline removal artifacts. Equatorial ligands are split into 2 distinct contributions (Figure 5A, peak B and C). In the crystal structure, the equatorial shells correspond to short uranyl monoamide distances and long uranyl nitrate distances. Three smaller peaks are observed at longer distances on the FT spectra and can be attributed to the nitrate nitrogen (peak D) and terminal oxygen (denoted O', peak F) atoms and to the two monoamide carbon atoms and/or multiple-scattering in the axial uranyl system (peak E). EXAFS best-fit parameters (interatomic distances and DW factors) are given in Tables 4 and 5.

Table 4. EXAFS best-fit parameters of U(VI) samples. Distances are restricted within $+/-10 \%$ of the solid-state values (U-DBBA-S). DW factors $\left(\sigma^{2}\right)$ are restricted between $10^{-3} \AA^{-1}$ and $3.10^{-2} \AA^{-}$ 1.

\begin{tabular}{|c|c|c|c|c|c|c|c|c|c|c|c|}
\hline \multicolumn{2}{|c|}{ Uranium } & \multicolumn{2}{|c|}{$\begin{array}{c}\text { U-DBBA-S } \\
S_{0}^{2}=0.85 \\
\Delta E^{0}=4.14 \mathrm{eV} \\
R f=2 \%\end{array}$} & \multicolumn{2}{|c|}{$\begin{array}{c}\text { U-DBBA-L } \\
S_{0^{2}}=1 \\
\Delta E^{0}=1.13 \mathrm{eV} \\
R f=3 \%\end{array}$} & \multicolumn{2}{|c|}{$\begin{array}{c}\text { U-DEHBA } \\
S_{O^{2}}=1 \\
\Delta E^{0}=5.25 \mathrm{eV} \\
R f=2 \%\end{array}$} & \multicolumn{2}{|c|}{$\begin{array}{c}\text { U-DEHDMBA } \\
S_{0}^{2}=1 \\
\Delta E^{0}=5.25 \mathrm{eV} \\
R f=2 \%\end{array}$} & \multicolumn{2}{|c|}{$\begin{array}{c}\text { U-DEHiBA } \\
S_{0}^{2}=1 \\
\Delta E^{0}=4.05 \mathrm{eV} \\
R f=1 \%\end{array}$} \\
\hline Path & $\mathbf{N}$ & $\sigma^{2}\left(\AA^{2}\right)$ & $\mathbf{R}(\stackrel{\mathbf{A}}{)})$ & $\sigma^{2}\left(\AA^{2}\right)$ & $\mathbf{R}(\AA)$ & $\sigma^{2}\left(\AA^{2}\right)$ & $\mathbf{R}(\AA)$ & $\sigma^{2}\left(\AA^{2}\right)$ & $\mathbf{R}(\AA)$ & $\sigma^{2}\left(\AA^{2}\right)$ & $\mathbf{R}(\AA)$ \\
\hline$U=O$ & 2 & 0.002 & $1.77(2)$ & 0.002 & $1.77(1)$ & 0.002 & 1.77(1) & 0.003 & 1.77(1) & 0.002 & 1.77(1) \\
\hline $\boldsymbol{U}$ - $\boldsymbol{O}_{\text {amide }}$ & 2 & 0.004 & $\mathbf{2 . 3 6}(2)$ & 0.008 & $\mathbf{2 . 3 6}(1)$ & 0.003 & $\mathbf{2 . 4 0}(2)$ & 0.005 & $\mathbf{2 . 4 0}(2)$ & 0.005 & $\mathbf{2 . 3 8}(2)$ \\
\hline $\mathrm{U}-\mathrm{O}_{\mathrm{NO}}$ & 4 & 0.005 & $\mathbf{2 . 5 4}(2)$ & 0.006 & $2.52(1)$ & 0.005 & $\mathbf{2 . 5 4}(2)$ & 0.006 & $\mathbf{2 . 5 4}(2)$ & 0.006 & $\mathbf{2 . 5 3}(1)$ \\
\hline$U-N_{N O 3}$ & 4 & 0.005 & $\mathbf{2 . 9 8}(1)$ & 0.006 & $\mathbf{2 . 9 6}(3)$ & 0.005 & $\mathbf{2 . 9 6}(2)$ & 0.003 & $2.97(1)$ & 0.004 & $2.97(3)$ \\
\hline$U$ - $C_{\text {amide }}$ & 2 & 0.006 & $\mathbf{3 . 6 1}(8)$ & 0.009 & $\mathbf{3 . 6 1}(6)$ & 0.028 & $\mathbf{3 . 4 7}(14)$ & 0.012 & $\mathbf{3 . 3 7}(8)$ & 0.012 & $\mathbf{3 . 3 3}(8)$ \\
\hline
\end{tabular}




\begin{tabular}{ll|ll|ll|ll|ll|ll}
$\boldsymbol{U}-\boldsymbol{O}^{\prime}{ }_{N 03}$ & $\mathbf{4}$ & 0.002 & $\mathbf{4 . 1 9}(1)$ & 0.003 & $\mathbf{4 . 1 5}(2)$ & 0.005 & $\mathbf{4 . 1 9}(2)$ & 0.004 & $\mathbf{4 . 2 2}(2)$ & 0.007 & $\mathbf{4 . 2 0}(2)$ \\
\hline
\end{tabular}

The Uranyl U-O $\mathrm{O}_{\mathrm{yl}}$ bond distance is constant for the five samples and equal to $1.77 \AA$. It is $0.03 \AA$ shorter than the XRD distances. Such difference in uranyl distances between the two techniques has been reported in the litterature and may be due to sample preparation. ${ }^{64}$ The $\mathrm{U}_{-} \mathrm{O}_{\mathrm{NO} 3}$ and U$\mathrm{N}_{\mathrm{NO} 3}$ distances are almost equivalent for the five samples $\left(2.52 \AA<\mathrm{d}\left(\mathrm{U}-\mathrm{O}_{\mathrm{NO} 3}\right)<2.54 \AA\right.$ and 2.96 $\left.\AA<\mathrm{d}\left(\mathrm{U}-\mathrm{N}_{\mathrm{NO} 3}\right)<2.98 \AA\right)$. The third oxygen atoms of the two nitrate molecules $\left(\mathrm{O}^{\prime}\right)$ are at longer distances and appeared to be more scattered over the five samples $\left(4.15 \AA<\mathrm{dU}-\mathrm{O}{ }^{\prime}{ }_{\mathrm{NO} 3}<4.23 \AA\right)$. The U-O $\mathrm{O}_{\text {amide }}$ distances differ slightly for the different U-DEHDMBA, U-DEHIBA and UDEHIBA complexes. U-O $\mathrm{O}_{\text {amide }}$ distances are shorter by $0.02 \AA$ with DEHiBA than with DEHDMBA. This shortening can be explained by the slightly higher electronic donation from DEHiBA compared to DEHDMBA. Unexpectedly, U-O $\mathrm{O}_{\text {amide }}$ distance with DBBA is shorter by 0.02 to $0.04 \AA$ than with the longer alkyl chain molecules (DEHiBA and DEHDMBA). It cannot be explained by similar electronic effect but it may be due to different medium effects, U-DBBA samples are solid-state compound or dissolved in toluene whereas DEHiBA and DEHDMBA samples were prepared in $\mathrm{n}$-dodecane, which is less polar. $\mathrm{U}-\mathrm{C}_{\text {amide }}$ distances differ more significantly in the different complexes. However, such differences have to be interpreted with care. The $\mathrm{C}_{\text {amide }}$ contribution to the EXAFS spectrum (peak E on Figure 5A) highly depends on $\mathrm{U}-\mathrm{O}_{\text {amide }}-\mathrm{C}_{\text {amide }}$ angle, which is held fixed to the crystallographic value $\left(165.5^{\circ}\right)$ in the fitting procedure. Hence, error bars as well as the DW factors $\left(\sigma^{2}>10^{-2} \AA^{-1}\right)$ are found to be large. The monoamides carbon atoms, not directly bound to uranium are in a disordered second coordination shell.

EXAFS fitting results obtained for uranium allows us to draw-up two main conclusions: 
- The uranyl coordination structure in organic solution for short and long alkyl chain monoamides is identical to its solid-state XRD structure obtained with a short chain monoamide.

- Distances and disorder in the uranyl equatorial plane are constant over all the samples for the bidentate nitrate ligand whereas small variations have been measured for $\mathrm{U}-\mathrm{O}_{\text {amide }}$ distances as a function of the alkyl group and of the media (solid-state, solutions in toluene or in $n$-dodecane).

Experimental EXAFS spectra for plutonium samples are presented in Figure 4B. As observed for uranium samples, frequencies and amplitudes of the experimental oscillations are similar for all the samples. However, some differences are present in the spectra of DEHIBA and DEHBA samples, even if they were recorded in the same experimental conditions (a superposition of the FTs is presented in Supporting Information, Figure S2). EXAFS spectra seem to be dominated by a single frequency oscillation in the low k region (below $8 \AA^{-1}$ ) and oscillations with higher frequency beatings appear above $8 \AA^{-1}$. The spectra are dominated by the first shell oxygen contributions as observed on the FT at $\mathrm{R}+\varphi=2 \AA$ (Figure 5B, peak G) which are likely to be split into more than one contribution (monoamide distances and nitrate distances). An intermediate contribution (shoulder $\mathrm{H}$ ) is attributed to the short $\mathrm{Pu}-\mathrm{N}$ interaction due to bidentate nitrate ligands. ${ }^{31}$ The last contribution at $\mathrm{R}+\varphi=3.6 \AA$ (peak I) is attributed to the terminal oxygen atoms from the nitrate molecules. The high amplitude of this peak highlights an important focusing effect ${ }^{65}$ in the quasi-linearity of $\mathrm{Pu}-\mathrm{N}-\mathrm{O}$, also characteristic of bidentate coordination mode for nitrate anion. It is well-known that linear three-body configuration greatly enhances the long-range interaction through the so-called focusing effect which generates strong 
multiple-scattering effects. In between peaks $\mathrm{H}$ and I, various features are observed $(2.7 \AA<$ $\mathrm{R}+\varphi<3.3 \AA$ ). According to the crystal structure, this contribution to the EXAFS spectrum might correspond to the monoamide carbon back-scatterer and multiple-scattering effects with the monoamide oxygen and carbon atoms. The amplitude and phase for multiple-scattering contribution strongly depend on monoamide $\mathrm{C}_{\text {amide }}-\mathrm{O}_{\text {amide }}$ bond length and on the Pu-O-C angle.

Metrical parameters obtained for plutonium complexes are presented in Table 5. For all plutonium(IV) samples, in contrast to uranyl, the EXAFS spectra are dominated by the first coordination shell composed of oxygen atoms from the four bidentate nitrate ions and the two monoamides. Moreover, in contrast to uranyl, two distinct $\mathrm{Pu}-\mathrm{O}_{\mathrm{NO}}$ distances have to be included in the fit in order to reproduce the first plutonium coordination shell. This is consistent with XRD results which give almost identical $\mathrm{U}_{-} \mathrm{O}_{\mathrm{NO} 3}$ distances $\left(2.525 \AA<\mathrm{d}\left(\mathrm{U}-\mathrm{O}_{\mathrm{NO} 3}\right)<2.527 \AA\right)$ and more dispersed $\mathrm{Pu}-\mathrm{O}_{\mathrm{NO} 3}$ distances $\left(2.418 \AA<\mathrm{d}\left(\mathrm{Pu}-\mathrm{O}_{\mathrm{NO} 3} \mathrm{XRD}\right)<2.470 \AA\right)$. The double $\mathrm{O}_{\mathrm{NO} 3}$ shell used in the fit (noted $\mathrm{O}_{\mathrm{NO}_{3}-1}$ and $\mathrm{O}_{\mathrm{NO}_{3}-2}$ in Table 5) resulted in a more accurate description of the plutonium structure, lowering R-factor values below 5\%, and providing more meaningful DW factor $\left(<10^{-2}\right)$. For the five samples, nitrate metrical parameters used to fit the nitrate contribution to EXAFS spectra are very similar to the XRD distances. $\mathrm{N}_{\mathrm{NO} 3}$ and $\mathrm{O}^{\prime}{ }_{\mathrm{NO} 3}$ shells are both in agreement with the crystal structure. So it is reasonable to conclude that the nitrate groups are mostly bidentate in the plutonium coordination sphere in all the studied samples both in the solid and liquid states. 
Table 5. EXAFS best-fit parameters of Pu(IV) samples. Distances are restricted within $+/-10 \%$ of the solid-state ones (Pu-DBBA-S $)$. DW factors $\left(\sigma^{2}\right)$ are restricted between $10^{-3} \AA^{-1}$ and $3.10^{-2}$ $\AA^{-1}$.

\begin{tabular}{|c|c|c|c|c|c|c|c|c|c|c|c|}
\hline \multicolumn{2}{|c|}{ Plutonium } & \multicolumn{2}{|c|}{$\begin{array}{c}\text { Pu-DBBA-S } \\
\\
S_{0^{2}}=0.9 \\
\Delta E^{0}=0.12 \mathrm{eV} \\
R f=4 \%\end{array}$} & \multicolumn{2}{|c|}{$\begin{array}{c}\text { Pu-DBBA-L } \\
S_{0^{2}}=1 \\
\Delta E^{0}=0.2 \mathrm{eV} \\
R f=4 \%\end{array}$} & \multicolumn{2}{|c|}{$\begin{array}{c}\text { Pu-DEHBA } \\
S_{0}{ }^{2}=1 \\
\Delta E^{0}=-1.5 \mathrm{eV} \\
R f=3 \%\end{array}$} & \multicolumn{2}{|c|}{$\begin{array}{c}\text { Pu-DEHDMBA } \\
S_{0^{2}}=1 \\
\Delta E^{0}=0.2 \mathrm{eV} \\
R f=3 \%\end{array}$} & \multicolumn{2}{|c|}{$\begin{array}{c}\text { Pu-DEHiBA } \\
S_{0^{2}}=1 \\
\Delta E^{0}=0.8 \mathrm{eV} \\
R f=3 \%\end{array}$} \\
\hline & $\mathbf{N}$ & 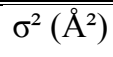 & $\bar{R}(\mathbf{A})$ & $\overline{\sigma^{2}\left(\AA^{2}\right)}$ & $\mathbf{R}(\AA)$ & $\overline{\sigma^{2}\left(\AA^{2}\right)}$ & $\bar{R} \mathbf{R}(\mathbf{\AA})$ & $\overline{\sigma^{2}\left(\AA^{2}\right)}$ & $\mathbf{R}(\AA)$ & $\bar{~} \sigma^{2}\left(\AA^{2}\right)$ & $\bar{R} \mathbf{R}(\AA)$ \\
\hline$P u-O_{\text {amide }}$ & 2 & 0.003 & $2.25(1)$ & 0.004 & $2.24(1)$ & 0.003 & $2.23(1)$ & 0.004 & $2.26(2)$ & 0.009 & $\mathbf{2 . 2 8}(2)$ \\
\hline $\mathrm{Pu}-\mathrm{O}_{\mathrm{NO}_{3}}-1$ & 4 & 0.006 & $2.41(1)$ & 0.005 & $2.39(1)$ & 0.003 & $2.39(1)$ & 0.004 & $\mathbf{2 . 4 0}(1)$ & 0.003 & $2.40(1)$ \\
\hline $\mathrm{Pu}-\mathrm{O}_{\mathrm{NO}}-2$ & 4 & 0.006 & $2.46(1)$ & 0.005 & $2.47(1)$ & 0.003 & $2.47(1)$ & 0.004 & $\mathbf{2 . 4 7}(1)$ & 0.003 & $\mathbf{2 . 5 0}(1)$ \\
\hline$P u-N_{N O 3}$ & 4 & 0.004 & $2.95(1)$ & 0.004 & $2.93(1)$ & 0.003 & $2.92(1)$ & 0.003 & $2.92(1)$ & 0.003 & $\mathbf{2 . 9 3}(1)$ \\
\hline$P u-C_{\text {amide }}$ & 2 & 0.009 & $3.35(6)$ & 0.008 & $3.38(3)$ & 0.013 & $\mathbf{3 . 1 7}(8)$ & 0.009 & $\mathbf{3 . 3 2}(3)$ & 0.007 & 3.19 (4) \\
\hline$P u-O_{N O 3}^{\prime}$ & 4 & 0.006 & $4.12(3)$ & 0.005 & $4.11(2)$ & 0.003 & $4.11(2)$ & 0.004 & $4.11(2)$ & 0.003 & $4.12(2)$ \\
\hline
\end{tabular}

Large variations between the linear and branched alkyl chain ligands are found in scattering paths that involve monoamide atoms $\left(\mathrm{O}_{\text {amide }}\right.$ and $\left.\mathrm{C}_{\text {amide }}\right)$. If the short $\mathrm{Pu}-\mathrm{O}_{\text {amide }}$ distance is consistent with $\mathrm{XRD}$ values for Pu-DBBA-S, it becomes longer as the sterical hindrance increases over the monoamide series (from $2.24 \AA$ for Pu-DBBA-L to $2.28 \AA$ for Pu-DEHiBA with an intermediate value of $2.26 \AA$ for Pu-DEHDMBA). A longer distance (+0.05 $\AA$ from PuDEHBA to Pu-DEHiBA) seems to be related with plutonium coordination sphere congestion. The concomitant increase of the DW factors (from $0.004 \AA^{-1}$ for Pu-DBBA to $0.009 \AA^{-1}$ for PuDEHiBA) confirms the trend. Pu-DEHiBA DW factor is the largest for this scattering path $\left(\sigma^{2}\right.$ $\left.\mathrm{O}_{\text {amide }}=0.009 \AA^{-1}\right)$. Conversely, the carbon shell $\left(\mathrm{C}_{\text {amide }}\right)$ distances are smaller for Pu-DEHBA, Pu-DEHiBA and Pu-DEHDMBA samples than for short alkyl chain ligand complexes (PuDBBA-S and Pu-DBBA-L). A shorter distance would indicate a bending of the pseudo linear 
$\mathrm{Pu}-\mathrm{O}_{\text {amide }}-\mathrm{C}_{\text {amide }}$ angle. However, as for uranium, the monoamides carbon atoms, not directly bound to plutonium are in a disordered second coordination shell. The model considering a fixed Pu-O-C angle $\left(162^{\circ}\right)$ spuriously increases DW factors in order to reduce the oscillation amplitudes. A poorest agreement with the experimental data is thus observed in the range of 2.7 $\AA<\mathrm{R}+\varphi<3.3 \AA$.

To conclude this section on plutonium, in spite of the differences found in the Pu-DEHBA and Pu-DEHiBA EXAFS spectra, it was possible to obtain a correct fit for both systems. However, we notice that the DW factor for the Pu- $\mathrm{O}_{\text {amide }}$ path of Pu-DEHiBA is particulary high $\left(\sigma^{2} \mathrm{O}_{\text {amide }}\right.$ $=0.009 \AA^{-1}$ ) and this may indicate that the crystallographic model is not the best suited for this system. This hypothesis is strengthened by the comparison of Vis-NIR solution spectra of PuDEHiBA and Pu-DEHBA (Figure 6). The two spectra have significant differences; a shift of the band at $480 \mathrm{~nm}$, the emerging of a band at $610 \mathrm{~nm}$ for Pu-DEHiBA and an inversion of the doublets intensities around $550 \mathrm{~nm}$. Such differences between Vis-NIR spectra of Pu-DEHiBA and Pu-DEHBA were previously reported at lower and higher nitric acid concentrations ${ }^{6}$ and are consistent with different geometries around $\mathrm{Pu}(\mathrm{IV})$ for the two monoamides. To investigate further this hypothesis, we performed theoretical calculations on $\mathrm{Pu}(\mathrm{IV})$ complexes. 




Figure 6. Vis-NIR absorption spectra of Pu-DEHIBA and Pu-DEHBA liquid samples.

\section{Theoretical calculations}

Different structural $\mathrm{Pu}(\mathrm{IV})$-monoamide complexes models were optimized through DFT and corresponding thermal DW factors were determined from the vibrational frequencies. For each geometry, the theoretical EXAFS spectrum was calculated and compared to the experimental ones. It should be stressed that the only adjusted parameter in the calculated EXAFS spectra is the photoelectron energy origin $\Delta \mathrm{E}_{0}$. In order to draw a comparison between DEHiBA and DEHBA, two model ligands with a branched or linear alkyl chain on the carbonyl were selected; N,N-diethylisobutanamide (DEiBA) and N,N-diethylpropionamide (DEPA) (Chart 1.) The alkyl chains were truncated in order to diminish computational time. This is a good approximation considering that EXAFS spectra contain information on interatomic distances up to about 5-6 $\AA$ 
and that longer alkyl chains shouldn't alter the EXAFS spectra. DEPA and DEiBA ligands will be respectively compared to DEHBA and DEHiBA.

We considered the structural models a, b, $\mathbf{c}$ and $\mathbf{d}$ described in Figure 7. The first complex is $\mathrm{Pu}\left(\mathrm{NO}_{3}\right)_{4} \mathbf{L}_{2}$ (a) with two inner-sphere amide ligands $\mathbf{L}$ and four bidentate nitrate corresponding to the XRD crystal structure previously used as a model for the EXAFS fitting procedure. The second complex is $\mathrm{Pu}\left(\mathrm{NO}_{3}\right)_{4} \mathbf{L}_{3}$ (b) with three inner sphere amide ligands $\mathbf{L}$ corresponding to the stoichiometry which has been suggested from solvent extraction data for some amides with branched alkyl groups. ${ }^{6}$ The third complex is $\mathrm{Pu}\left(\mathrm{NO}_{3}\right)_{6}(\mathbf{H L})_{2}$ (c) corresponding to $\mathrm{Pu}\left(\mathrm{NO}_{3}\right)_{6}{ }^{2-}$ with two $\mathbf{H L}^{+}$protonated monoamides in the cation outer-coordination sphere hydrogen-bonded to the nitrate ions. $N, N$-dialkyl Amides are known to undergo protonation at high nitric acid concentration and the presence of such anionic species has been suggested in previous reports at high nitric acid concentration $\left[\mathrm{HNO}_{3}\right]>6 \mathrm{M} .{ }^{6,26}$. For DEiBA ligand, a fourth complex was taken into account; $\mathrm{Pu}\left(\mathrm{NO}_{3}\right)_{5} \mathbf{L}(\mathbf{H L})(\mathbf{d})$ corresponding to $\mathrm{Pu}\left(\mathrm{NO}_{3}\right)_{5} \mathbf{L}^{-}$with one $\mathbf{H L}^{+}$protonated ligand hydrogen-bonded to one nitrate ion.
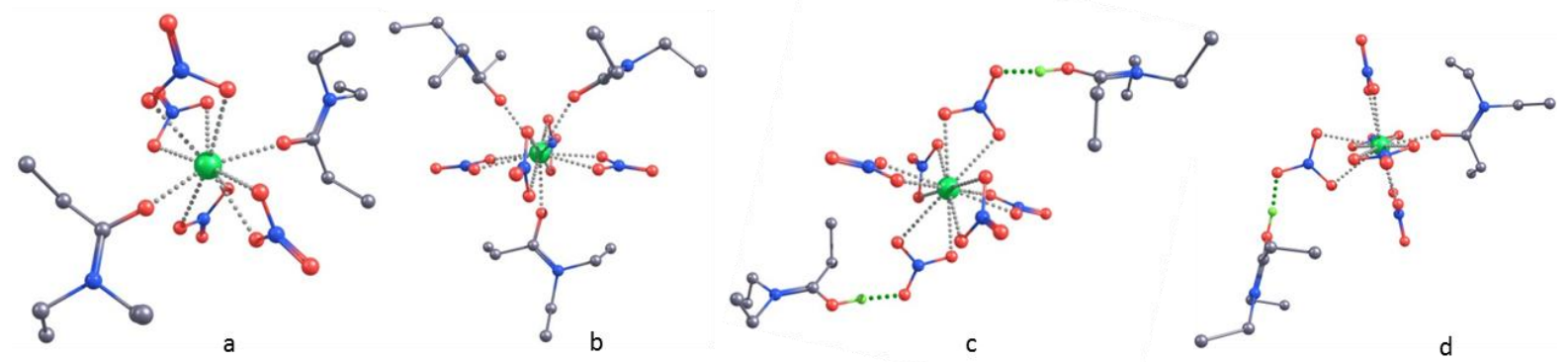

Figure 7. DFT-optimized geometries of $\mathrm{Pu}\left(\mathrm{NO}_{3}\right)_{4} \mathbf{L}_{2}(\mathbf{a}), \mathrm{Pu}\left(\mathrm{NO}_{3}\right)_{4} \mathbf{L}_{3}(\mathbf{b}), \mathrm{Pu}\left(\mathrm{NO}_{3}\right)_{6}(\mathrm{HL})_{2}$ (c) $\mathrm{Pu}\left(\mathrm{NO}_{3}\right)_{5} \mathbf{L}(\mathrm{HL})(\mathbf{d})$ 
On Figure 8, the calculated EXAFS spectra for Pu-DEPA complexes with structures $\mathbf{a}, \mathbf{b}$ and $\mathbf{c}$ are compared to the experimental one recorded for Pu-DEHBA. Provided that no interatomic distances or Debye-Waller factors have been fitted, the spectrum simulated for a exhibits an excellent agreement with the experimental one. Concerning the $\mathrm{k}^{3} \chi(\mathrm{k})$ curve, the first oscillations are almost superimposed and a small phase shift emerges after $6.5 \AA^{-1}$. On the Fourier transform, the two major peaks are very well reproduced. As previously mentioned, contributions below 1.2 $\AA$ are low frequencies spline removal artifacts. The only discrepancy occurs in the intermediate region $(2.6 \AA-3.2 \AA)$ where the signal is not very well reproduced. This can be attributed to the flexibility of the carbonyl carbon atoms which are not directly bound to $\mathrm{Pu}(\mathrm{IV})$. Debye-Waller terms account for thermal and structural disorders, while in our calculations only the thermal disorder is taken into account. Structural disorder is expected to be significant for such unbound atoms. The calculated spectrum for b doesn't reproduce as well as a the experimental spectrum. The first oscillations and the first FT peaks are not very well described. Model c gives really poor agreement with experimental spectrum. The very intense first oscillations and first peak on the Fourier transform are due to higher coordination number in the inner coordination shell (twelve oxygen atoms). To summarize, as expected from XRD and EXAFS results, for a linear alkyl chain amide, complex $\mathbf{a}$ is the most likely predominant species in solution. 

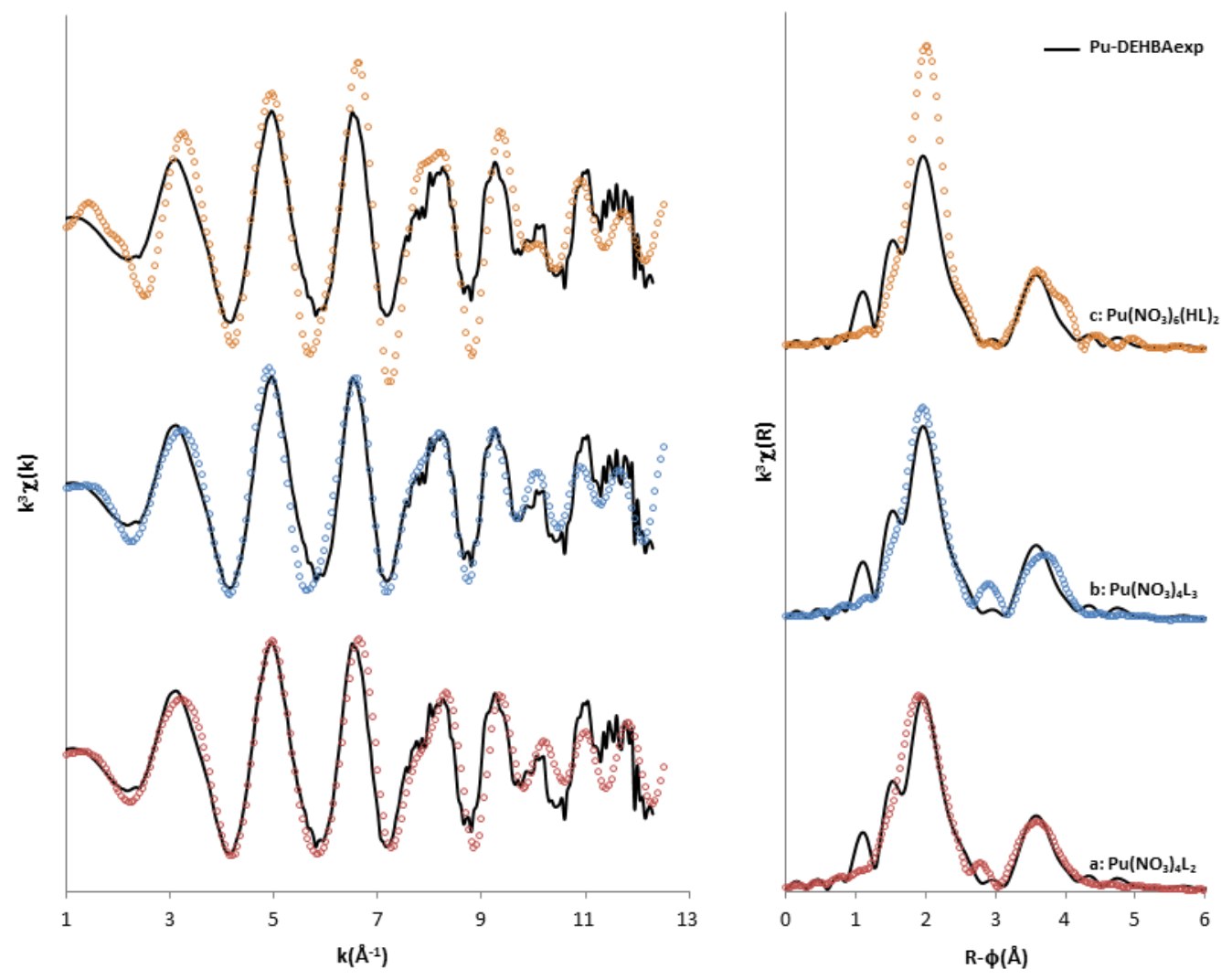

Figure 8. $\mathrm{k}^{3}$-weighted experimental EXAFS spectrum of Pu-DEHBA sample (solid black line) compared to theoretical EXAFS spectra of Pu-DEPA in a (red), b (blue) and c (orange) geometries (left) and corresponding Fourier transfoms (right).

Table 6. Selected bond distances (average values in $\AA$ ) and Debye-Waller factor $\sigma^{2}\left(\AA^{2}\right)$ from DFT calculations in $\mathrm{Pu}\left(\mathrm{NO}_{3}\right)_{4}(\text { DEPA })_{2}$ and $\mathrm{Pu}\left(\mathrm{NO}_{3}\right)_{4}(\text { DEiBA })_{2}$ (geometry a)

\begin{tabular}{lcccc}
\hline & \multicolumn{2}{c}{$\mathrm{Pu}\left(\mathrm{NO}_{3}\right)_{4}(\text { DEPA })_{2}$} & \multicolumn{2}{c}{$\mathrm{Pu}\left(\mathrm{NO}_{3}\right)_{4}(\mathbf{D E i B A})_{2}$} \\
& distance & $\sigma^{2}$ & distance & $\sigma^{2}$ \\
\hline \hline $\mathrm{Pu}-\mathrm{O}_{\text {amide }}$ & 2.30 & 0.003 & 2.33 & 0.003 \\
$\mathrm{Pu}-\mathrm{O}_{\mathrm{NO} 3}$ & 2.43 & 0.006 & 2.47 & 0.007
\end{tabular}




\begin{tabular}{ccccc}
$\mathrm{Pu}-\mathrm{O}_{\mathrm{NO} 3}$ & 2.46 & 0.007 & 2.51 & 0.008 \\
$\mathrm{Pu}-\mathrm{N}_{\mathrm{NO} 3}$ & 2.89 & 0.003 & 2.94 & 0.004 \\
$\mathrm{Pu}-\mathrm{C}_{\mathrm{amide}}$ & 3.45 & 0.003 & 3.60 & 0.003 \\
$\mathrm{Pu}{ }{ }_{\mathrm{NO} 3}$ & 4.08 & 0.004 & 4.16 & 0.004 \\
\hline
\end{tabular}

DFT calculated structural parameters and DW factors are given in Table 6 for model a. Overall, calculated parameters for Pu-DEPA agree very well with EXAFS and XRD results. Interatomic distances between $\mathrm{Pu}$ and nitrate atoms are totally consistent with EXAFS best-fit and XRD values. The calculated $\mathrm{Pu}-\mathrm{O}_{\text {amide }}$ distance $(2.30 \AA)$ is found slightly longer than XRD value for Pu-DBBA (2.26 $\AA$ ) and EXAFS best-fit value for Pu-DEHBA (2.23 $\AA$ ), but the DW factors are found equal nonetheless $\left(0.003 \AA^{2}\right)$. The two calculated $\mathrm{Pu}-\mathrm{O}_{\mathrm{NO} 3}$ distances $(2.43$ and $2.46 \AA)$ match very well the XRD ones (2.44 and $2.46 \AA$ ), and are coherent with the EXAFS best-fit values $(2.39-2.47 \AA)$. EXAFS fit gives DW for $\mathrm{Pu}-\mathrm{O}\left(\mathrm{NO}_{3}\right)$ paths which are about two times smaller than the calculated values. It is very unlikely that calculated DW are underestimated since structural disorder is neglected and should increase DW values. Therefore, the large splitting of the two $\mathrm{Pu}-\mathrm{O}_{\mathrm{NO} 3}$ distances in EXAFS fit can be attributed to an artificial compensation for underestimated best-fit DW values. The calculated Pu-C distance ( $3.45 \AA$ ) is very close to the XRD one $(3.47 \AA)$ but the EXAFS best-fit DW $\left(0.013 \AA^{2}\right)$ is much larger than the calculated one $\left(0.003 \AA^{2}\right)$. Once again, this can be attributed to the structural disorder of the unbound carbon atom, which is not taken into account in the present DW calculations.

Finally, it's noteworthy that for DEHBA, several structural hypotheses were tested but the calculations come up with a structure which is fully consistent with DRX and EXAFS results $\left(\mathrm{Pu}\left(\mathrm{NO}_{3}\right)_{4} \mathbf{L}_{2}\right)$. A very good agreement is found between the theoretical and experimental spectrum, while it is not possible to reproduce the spectra with the other structural models. 
Hence, the present methodology enables to test different structural hypotheses and discard the ones that are not well suited.
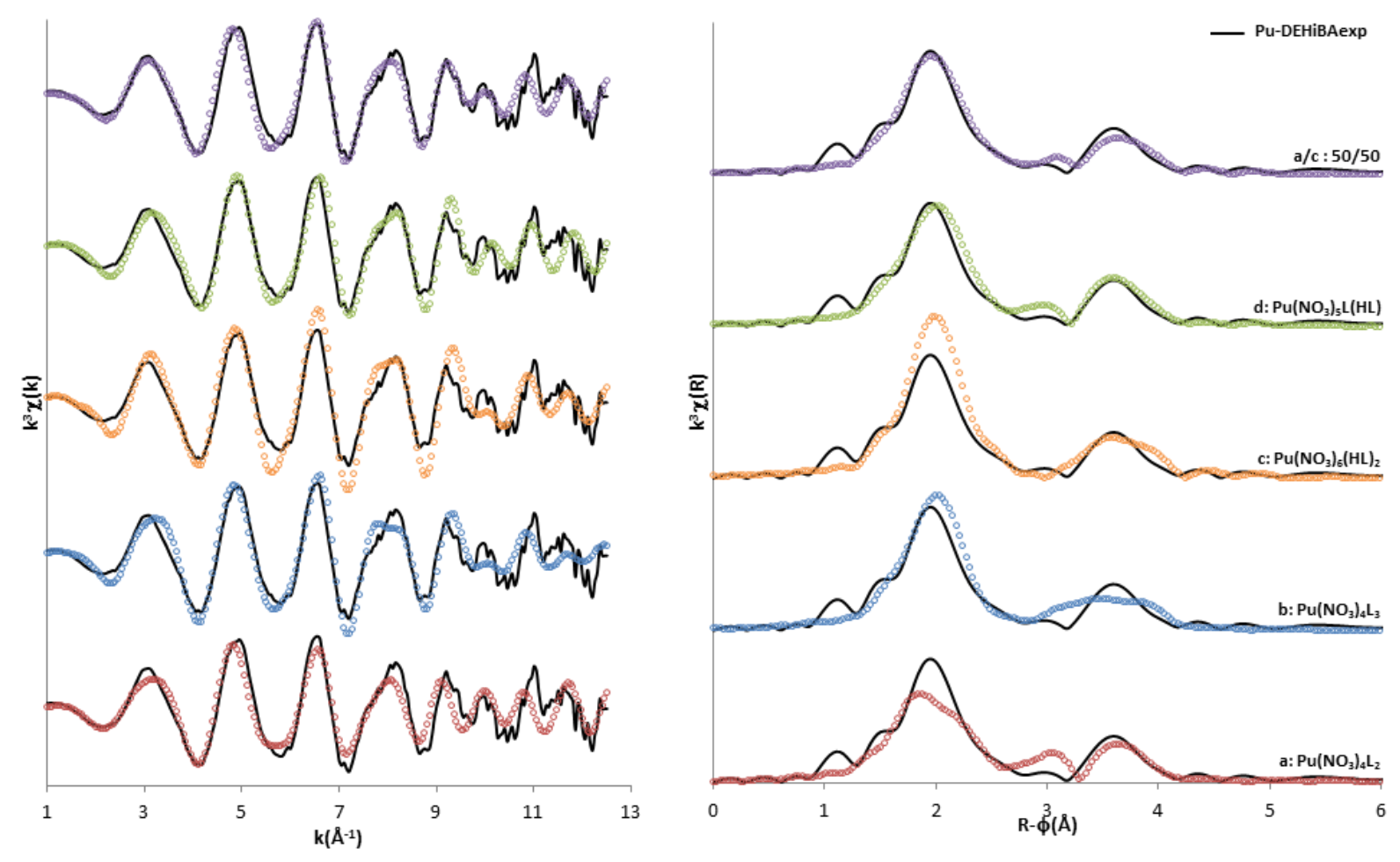

Figure 9. $\mathrm{k}^{3}$-weighted experimental EXAFS spectrum of Pu-DEHiBA sample (solid black line) compared to theoretical EXAFS spectra of Pu-DEiBA in a (red), b (blue), c (orange), $\mathbf{d}$ (green) and $\mathbf{a} / \mathbf{c}$ (purple) geometries (left) and corresponding Fourier transforms (right).

Calculated EXAFS spectra for Pu-DEiBA are presented on Figure 9. Contrary to Pu-DEHBA results, the structure a spectrum does not reproduce the Pu-DEHiBA experimental spectrum: the oscillations and the first FT peak lack intensity, which is consistent with the difficulties 
encountered in the EXAFS fitting procedure using the XRD structural model. Structural data obtained from DFT calculations are given in Table 6. Inner shell interatomic distances are slightly longer in Pu-DEPA than Pu-DEiBA (model a), $\mathrm{Pu}-\mathrm{O}_{\text {amide }}$ and $\mathrm{Pu}-\mathrm{O}_{\mathrm{NO}}$ distances are lengthened by $0.03 \AA$ and $0.05 \AA$, respectively. Agreement with experimental spectrum is not improved using $\mathbf{b}$ and $\mathbf{c}$ models. None of the three structural models fits the experimental data correctly. However it is possible that $\mathrm{Pu}(\mathrm{IV})$ adopts several coordination structures and that several plutonium species co-exist in solution. To investigate this hypothesis, we calculated the EXAFS spectra corresponding to a mix of $\mathbf{a}, \mathbf{b}, \mathbf{c}$ complexes. A linear combination of the three calculated $\mathrm{k}^{3} \chi(\mathrm{k})$ spectra was adjusted to the experimental spectrum with ATHENA software. ${ }^{39}$ The best-fit was obtained for an equal mixing of $\mathbf{a}$ and $\mathbf{c}(0.53(\mathbf{a})+0(\mathbf{b})+(0.47(\mathbf{c}))$. The best-fit result is presented in Figure 9. The $\mathrm{k}^{3} \chi(\mathrm{k})$ oscillations are almost superimposed with the experimental spectrum and the shape of the Fourier transform is very well reproduced. By introducing three adjusted mixing parameters in the calculation, it's not unexpected that a very good agreement with experimental data is obtained. However, it seems reasonable that in the presence of branched alkyl groups, the increase of steric hindrance around $\mathrm{Pu}(\mathrm{IV})$ favours the formation of outer sphere complexes c. To further investigate the presence of outer sphere complexation, the fourth structural model $\mathbf{d}$ (Figure 7) with one inner-sphere and one outersphere ligand was considered. If anionic $\mathrm{Pu}\left(\mathrm{NO}_{3}\right)_{3}(\mathbf{H L})_{2}$ species were proposed in the litterature at $\left[\mathrm{HNO}_{3}\right]>6 \mathrm{M}, \mathrm{Pu}\left(\mathrm{NO}_{3}\right)_{5}(\mathrm{HL}) \mathbf{L}$ has not been reported but its presence as an intermediate species at lower acidity $(3 \mathrm{M})$ is realistic as an intermediate species between (a) and (c). The calculated and experimental spectra are in excellent agreement (Figure 9). It is difficult to discriminate between the two hypothesis, formation of mixing of $\mathbf{a}$ and $\mathbf{c}$ species or formation of d but they are equivalent since they lead to the same conclusion: they support that, in these 
experimental conditions and unlike DEHBA, the branched alkyl DEHiBA forms both outersphere and inner-sphere complexes.

It is worth noting that an apparent increase of stoichiometric number of amide ligands from 2 to

3 has been recently obtained in our laboratory from the "slope analysis" method ${ }^{66}$ It is consistent with our results since in our model one or two ligands are engaged in outer-sphere complexation but there is room in the outer-sphere for additional protonated ligands hydrogen-bonded to coordinated nitrate ions. The introduction of additional outer-sphere ligands shouldn't modify the calculated EXAFS spectrum since EXAFS only probes the metal ion inner coordination sphere.

\section{Conclusion}

The coordination structures of $\mathrm{U}(\mathrm{VI})$ and $\mathrm{Pu}(\mathrm{IV})$ ions with linear and branched alkyl monoamides have been reported here. A new plutonium(IV) crystal structure has been obtained. $\mathrm{U}(\mathrm{VI})$ displays identical structures in the solid state and in solution, as previously reported for other $N, N$-dialkyl amides: two amide ligands and four bidentate nitrate ions coordinate the uranyl ion. With linear alkyl amides, $\mathrm{Pu}(\mathrm{IV})$ also adopt identical structures in the solid state and in solution: $\mathrm{Pu}(\mathrm{IV})$ complexes contain two amides and four bidentate nitrate ions. With branched alkyl chain amides, EXAFS analysis supported by theoretical calculation reveals that $\mathrm{Pu}(\mathrm{IV})$ displays different coordination structures than those observed with linear alkyl chains amides in solution. While, the linear alkyl chains amide DEHBA form predominantly inner-sphere complexes, our study indicates that the branched alkyl DEHiBA form both inner-sphere and outer-sphere complexes with protonated ligands hydrogen bonded to nitrate ions. This behavior may explain the lower extracting power of DEHiBA toward Pu(IV) compared to DEHBA. ${ }^{6,9}$ The formation of such complexes should be favored by steric hindrance in $\mathrm{Pu}(\mathrm{IV})$ coordination 
sphere in presence of bulky substituent. It should also be highly dependent upon nitric acid concentration and be favored by high nitric acid concentration in aqueous solution.

Finally, we have shown that recent advances in EXAFS simulations ${ }^{34}$ can be particularly fruitful for EXAFS data analysis and to probe actinide coordination structure in solution. It's by performing EXAFS simulations based on structural parameters and Debye-Waller factors derived from DFT calculations that we were able to uncover differences in $\mathrm{Pu}(\mathrm{IV})$ coordination structures. It is the first application on actinide complexes and the results indicate that it is a very promising approach to probe actinides coordination sphere in solution. 


\section{REFERENCES}

1. $\quad$ Siddall, T. H., Journal of Physical Chemistry 1960, 64, 1863-1866.

2. $\quad$ Fritz, J. S.; Orf, G. M., Analytical Chemistry 1975, 47, 2043-2045.

3. Gasparini, G. M.; Grossi, G., Solvent Extraction and Ion Exchange 1986, 4, 1233-1271.

4. Musikas, C.; Hubert, H., Solvent Extraction and Ion Exchange 1987, 5, 877-893.

5. Ruikar, P. B.; Nagar, M. S.; Pai, S. A.; Subramanian, M. S., Journal of Radioanalytical and Nuclear Chemistry-Articles 1991, 150, 473-481.

6. Condamines, N.; Musikas, C., Solvent Extraction and Ion Exchange 1992, 10, 69-100.

7. Prabhu, D. R.; Mahajan, G. R.; Nair, G. M.; Subramanian, M. S., Radiochimica Acta 1993, 60, 109-113.

8. Nair, G. M.; Mahajan, G. R.; Prabhu, D. R., Journal of Radioanalytical and Nuclear Chemistry-Articles 1995, 191, 323-330.

9. Prabhu, D. R.; Mahajan, G. R.; Nair, G. M., Journal of Radioanalytical and Nuclear Chemistry 1997, 224, 113-117.

10. Suzuki, S.; Tamura, K.; Tachimori, S.; Usui, Y., Solvent Extraction Research and Development-Japan 1999, 6, 72-79.

11. Gupta, K. K.; Manchanda, V. K.; Subramanian, M. S.; Singh, R. K., Separation Science and Technology 2000, 35, 1603-1617.

12. Vasudevan, T.; Murali, M. S.; Nagar, M. S.; Mathur, J. N., Solvent Extraction and Ion Exchange 2002, 20, 665-686.

13. Manchanda, V. K.; Pathak, P. N., Separation and Purification Technology 2004, 35, 85103.

14. Cui, Y.; Sun, G. X.; Zhang, Z. W.; Li, Y. X.; Sun, S. X., Radiochimica Acta 2005, 93, 287-290.

15. Ban, Y.; Hotoku, S.; Morita, Y., Solvent Extraction and Ion Exchange 2011, 29, 519-533.

16. Pathak, P. N.; Prabhu, D. R.; Kumari, N.; Kanekar, A. S.; Manchanda, V. K., Desalination and Water Treatment 2012, 38, 40-45.

17. Rodrigues, F.; Ferru, G.; Berthon, L.; Boubals, N.; Guilbaud, P.; Sorel, C.; Diat, O.; Bauduin, P.; Simonin, J. P.; Morel, J. P.; Morel-Desrosiers, N.; Charbonnel, M. C., Molecular Physics 2014, 112, 1362-1374.

18. Verma, P. K.; Pathak, P. N.; Kumari, N.; Sadhu, B.; Sundararajan, M.; Aswal, V. K.; Mohapatra, P. K., Journal of Physical Chemistry B 2014, 118, 14388-14396.

19. $\quad$ Sieffert, N.; Wipff, G., Dalton Transactions 2015, 44, 2623-2638.

20. Pathak, P. N.; Kumbhare, L. B.; Manchanda, V. K., Radiochimica Acta 2001, 89, 447452.

21. Pathak, P. N.; Kumbhare, L. B.; Manchanda, V. K., Solvent Extraction and Ion Exchange 2001, 19, 105-126.

22. Nair, G. M.; Prabhu, D. R.; Mahajan, G. R., Journal of Radioanalytical and Nuclear Chemistry-Articles 1994, 182, 393-399.

23. Gupta, K. K.; Manchanda, V. K.; Subramanian, M. S.; Singh, R. K., Radiochimica Acta 1999, 85, 103-106.

24. Descouls, N.; Musikas, C., Journal of the Less-Common Metals 1986, 122, 265-274. 
25. Nair, G. M.; Mahajan, G. R.; Prabhu, D. R., Journal of Radioanalytical and Nuclear Chemistry-Articles 1996, 204, 103-111.

26. Gupta, K. K.; Manchanda, V. K.; Subramanian, M. S.; Singh, R. K., Solvent Extraction and Ion Exchange 2000, 18, 273-292.

27. Martingil, J.; Martingil, F. J.; Perales, A.; Fayos, J.; Martinezripoll, M., Acta Crystallographica Section C-Crystal Structure Communications 1983, 39, 44-45.

28. Kannan, S.; Deb, S. B.; Gamare, J. S.; Drew, M. G. B., Polyhedron 2008, 27, 2557-2562.

29. Charpin, P.; Lance, M.; Nierlich, M.; Vigner, D.; Musikas, C., Acta Crystallographica Section C-Crystal Structure Communications 1987, 43, 231-233.

30. Charpin, P.; Lance, M.; Nierlich, M.; Vigner, D.; Descouls, N.; Musikas, C., Acta Crystallographica Section C-Crystal Structure Communications 1986, 42, 560-563.

31. Den Auwer, C.; Revel, R.; Charbonnel, M. C.; Presson, M. T.; Conradson, S. D.; Simoni, E.; Le Du, J. F.; Madic, C., Journal of Synchrotron Radiation 1999, 6, 101-104.

32. Veronesi, G.; Boschi, C. D. E.; Ferrari, L.; Venturoli, G.; Boscherini, F.; Vila, F. D.; Rehr, J. J., Physical Review B 2010, 82.

33. Rehr, J. J.; Albers, R. C., Reviews of Modern Physics 2000, 72, 621-654.

34. Rehr, J. J.; Kas, J. J.; Prange, M. P.; Sorini, A. P.; Takimoto, Y.; Vila, F., Comptes Rendus Physique 2009, 10, 548-559.

35. Bruker APEX2, 4.0; Bruker AXS Inc.: Madison, WI, USA, 2013.

36. Bruker SAINT-Plus, 6.22; Bruker AXS Inc.: Madison, WI, USA, 2001.

37. Bruker SADABS, 2.03; Bruker AXS Inc.: Madison, WI, USA, 2001.

38. Sheldrick, G. M., Acta Crystallographica Section A 2008, 64, 112-122.

39. Ravel, B.; Newville, M., Journal of Synchrotron Radiation 2005, 12, 537-541.

40. Den Auwer, C.; Simoni, E.; Conradson, S.; Madic, C., European Journal of Inorganic Chemistry 2003, 3843-3859.

41. Morss, L. R.; Edelstein, N.; Fuger, J.; Klatz, J. J., The Chemistry of Actinide and Transactinide Elements. Springer: Dordrecht, 2006; Vol. 5.

42. Frisch, M. J.; Trucks, G. W.; Schlegel, H. B.; Scuseria, G. E.; Robb, M. A.; Cheeseman, J. R.; Scalmani, G.; Barone, V.; Mennucci, B.; Petersson, G. A.; Nakatsuji, H.; Caricato, M.; Li, X.; Hratchian, H. P.; Izmaylov, A. F.; Bloino, J.; Zheng, G.; Sonnenberg, J. L.; Hada, M.; Ehara, M.; Toyota, K.; Fukuda, R.; Hasegawa, J.; Ishida, M.; Nakajima, T.; Honda, Y.; Kitao, O.; Nakai, H.; Vreven, T.; Montgomery Jr., J. A.; Peralta, J. E.; Ogliaro, F. o.; Bearpark, M. J.; Heyd, J.; Brothers, E. N.; Kudin, K. N.; Staroverov, V. N.; Kobayashi, R.; Normand, J.; Raghavachari, K.; Rendell, A. P.; Burant, J. C.; Iyengar, S. S.; Tomasi, J.; Cossi, M.; Rega, N.; Millam, N. J.; Klene, M.; Knox, J. E.; Cross, J. B.; Bakken, V.; Adamo, C.; Jaramillo, J.; Gomperts, R.; Stratmann, R. E.; Yazyev, O.; Austin, A. J.; Cammi, R.; Pomelli, C.; Ochterski, J. W.; Martin, R. L.; Morokuma, K.; Zakrzewski, V. G.; Voth, G. A.; Salvador, P.; Dannenberg, J. J.; Dapprich, S.; Daniels, A. D.; Farkas, ñ. n.; Foresman, J. B.; Ortiz, J. V.; Cioslowski, J.; Fox, D. J. Gaussian 09, Revision D.01; Gaussian, Inc.: Wallingford, CT, USA, 2009.

43. Adamo, C.; Barone, V., Journal of Chemical Physics 1999, 110, 6158-6170.

44. Kuchle, W.; Dolg, M.; Stoll, H.; Preuss, H., Journal of Chemical Physics 1994, 100, 7535-7542.

45. Cao, X. Y.; Dolg, M., Journal of Molecular Structure-Theochem 2004, 673, 203-209.

46. Cao, X. Y.; Dolg, M.; Stoll, H., Journal of Chemical Physics 2003, 118, 487-496.

47. Schafer, A.; Huber, C.; Ahlrichs, R., Journal of Chemical Physics 1994, 100, 5829-5835.

48. Vila, F. D.; Lindahl, V. E.; Rehr, J. J., Physical Review B 2012, 85. 
49. Rehr, J. J.; Kas, J. J.; Vila, F. D.; Prange, M. P.; Jorissen, K., Physical Chemistry Chemical Physics 2010, 12, 5503-5513.

50. Kannan, S.; Barnes, C. L.; Duval, P. B., Chemical Communications 2005, 5997-5998.

51. Charpin, P.; Folcher, G.; Lance, M.; Nierlich, M.; Vigner, D., Acta Crystallographica Section C-Crystal Structure Communications 1985, 41, 1302-1305.

52. Zhu, L. M.; Cao, Z. B.; Li, B. L.; Wang, Y. L.; Yu, K. B., Chinese Journal of Structural Chemistry 2002, 21, 501-504.

53. Varga, T. R.; Benyei, A. C.; Fazekas, Z.; Tomiyasu, H.; Ikeda, Y., Inorganica Chimica Acta 2003, 342, 291-294.

54. Takao, K.; Noda, K.; Morita, Y.; Nishimura, K.; Ikeda, Y., Crystal Growth \& Design 2008, 8, 2364-2376.

55. Koshino, N.; Harada, M.; Nogami, M.; Morita, Y.; Kikuchi, T.; Ikeda, Y., Inorganica Chimica Acta 2005, 358, 1857-1864.

56. de Aquino, A. R.; Isolani, P. C.; Zukerman-Schpector, J.; Zinner, L. B.; Vicentini, G., Journal of Alloys and Compounds 2001, 323, 18-21.

57. Burns, P. C.; Ewing, R. C.; Hawthorne, F. C., Canadian Mineralogist 1997, 35, 15511570.

58. Bartlett, J. R.; Cooney, R. P., Journal of Molecular Structure 1989, 193, 295-300.

59. Clement, O.; Rapko, B. M.; Hay, B. P., Coordination Chemistry Reviews 1998, 170, 203 243.

60. Bagnall, K. W.; Beddoes, R. L.; Mills, O. S.; Xingfu, L., Journal of the Chemical Society-Dalton Transactions 1982, 1361-1364.

61. Shannon, R. D., Acta Crystallographica Section A 1976, 32, 751-767.

62. Matonic, J. H.; Enriquez, A. E.; Scott, B. L.; Paine, R. T.; Neu, M. P., Journal of Nuclear Science and Technology 2002, 39, 400-405.

63. Yaita, T.; Narita, H.; Suzuki, S.; Tachimori, S.; Shiwaku, H.; Motohashi, H., Journal of Alloys and Compounds 1998, 271, 184-188.

64. Thompson, H. A.; Brown, G. E.; Parks, G. A., American Mineralogist 1997, 82, 483-496.

65. Zhang, H. H.; Filipponi, A.; DiCicco, A.; Scott, M. J.; Holm, R. H.; Hedman, B.; Hodgson, K. O., Journal of the American Chemical Society 1997, 119, 2470-2478.

66. Rodrigues, F.; Charbonnel, M. C., Private communication. 